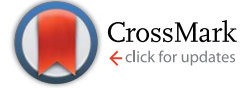

Cite this: Energy Environ. Sci., 2015, 8 , 1092

Received 9th December 2014

Accepted 26th January 2015

DOI: $10.1039 / c 4 e e 03875 d$

www.rsc.org/ees

\section{Biophotovoltaics: oxygenic photosynthetic organisms in the world of bioelectrochemical systems $\uparrow$}

\author{
Alistair J. McCormick, ${ }^{* a}$ Paolo Bombelli, ${ }^{\text {b }}$ Robert W. Bradley, ${ }^{\star c}$ Rebecca Thorne, ${ }^{d}$ \\ Tobias Wenzel ${ }^{\mathrm{e}}$ and Christopher J. Howe ${ }^{\star b}$
}

The field of bioelectrochemical system (BES) research includes a wide range of emerging technologies that utilise microbes to catalyze anodic and/or cathodic reactions within a fuel cell setup, and has developed greatly in the last 2-3 years. Although the vast majority of BESs utilise organic substrates as a fuel source (e.g. microbial fuel cells), several systems have been developed that are fuelled by light energy. In this review we focus on and contextualise a specific subset of light-harvesting BESs, which we have called biophotovoltaic systems (BPVs). BPVs utilise oxygenic photosynthetic organisms, such as microalgal and cyanobacterial species, to harvest light energy to generate current, critically, in the absence of an organic feedstock. Here we discuss the state-of-the-art for all light-harvesting BESs and present a novel classification system to illustrate how BPVs integrate into the broad fields of BES and photovoltaic research. We compare and contrast the present understanding of electron transfer pathways in systems that use heterotrophic microbes with those in cyanobacteria-based BPVs. Finally we present, for the first time, an estimate of the achievable power outputs of this emerging technology.

\begin{abstract}
Broader context
Biophotovoltaic systems (BPVs) use oxygenic photosynthetic organisms to harvest light energy and deliver electrical outputs. Similar to other light harvesting bioelectrochemical systems (BESs), BPVs have an advantage over photovoltaic systems in that the photo sensitive components are assembled and maintained by living organisms that are capable of self-repair, reproduction, and are able to store energy for power generation in the dark. This review compares the performances of other light harvesting BESs with BPVs and discusses our present understanding of exoelectrogenic activity in cyanobacteria. Current and power outputs for BPVs remain too low to produce energy on a commercial scale. However, here we estimate achievable outputs and conclude that performances of present BPV systems are still far below the theoretical maximum. We therefore hope that BPV technology will eventually develop into another valuable tool for the global switch away from carbon-intensive primary energy production.
\end{abstract}

\section{Introduction}

Life depends on the transfer of electrons between different biochemical intermediates to discharge or capture energy, or drive chemical change. The ability of certain microbes to facilitate the direct and/or indirect transfer of electrons outside of the cell (referred to as 'exoelectrogenic activity'), ${ }^{1}$ which can

${ }^{a}$ SynthSys and Institute of Molecular Plant Sciences, School of Biological Sciences, University of Edinburgh, EH9 3BF, UK

${ }^{b}$ Department of Biochemistry, University of Cambridge, Hopkins Building, Downing Site, CB2 1QW, UK. E-mail: ch26@cam.ac.uk

${ }^{c}$ Department of Life Sciences, Imperial College London, Sir Alexander Fleming Building, SW7 2AZ, UK

${ }^{d}$ Department of Environmental Impacts and Economics, Norwegian Institute for Air Research, PO Box 100, NO-2027 Kjeller, Norway

${ }^{e}$ Department of Physics, University of Cambridge, Cavendish Laboratory, Kapitza Building, CB3 OHE, UK

$\dagger$ Electronic supplementary information (ESI) available. See DOI: 10.1039/c4ee03875d then be harvested for reductive power, has driven the development of a variety of devices in which living organisms directly generate electrical power, which may also be coupled to separate reductive processes in the devices. These are collectively known as bioelectrochemical systems (BESs), ${ }^{2,3}$ and the last three decades have seen an exponential increase in scientific and industrial interest in them (Fig. 1 and 2). One of the most promising technologies to emerge is BESs fuelled by light energy. This development is of particular importance because of the nearly limitless supply of energy offered by solar radiation. ${ }^{4}$

The relatively sudden proliferation of studies involving lightharvesting BESs has led to the generation of a large variety of different system designs (Fig. 1 and 2). One important distinction between systems is whether an external fuel source other than light is used to drive current production. For example, devices that have used chemoautotrophs ${ }^{5,6}$ or mixed phototrophic and heterotrophic cultures ${ }^{6,7}$ typically rely on the addition of a feedstock of reducing equivalents (e.g. acetate) 
(Fig. 2A-C). Such systems are currently well documented in the literature (e.g. ref. 8 and 9).

Our main focus here is on systems that do not require an organic substrate, and use only oxygenic photosynthetic organisms, or parts of the oxygenic photosynthetic apparatus, to harvest light energy to generate current without the mediation of heterotrophic microbes. For simplicity (and with no intention to claim superiority) we have adopted the term biophotovoltaic system (BPV) to describe these devices (Fig. 2D). As will be defined here, BPVs can include a wide variety of subcellular or cellular photosynthetic components, such as purified oxygenic photosynthetic reaction centres (photosystem II, PSII) ${ }^{10,11}$ thylakoid membranes, ${ }^{12}$ cyanobacteria ${ }^{13,14}$ or green algae. ${ }^{15}$ In focusing, for the sake of brevity, on devices that do not require the mediation of heterotrophic microbes, we are thereby excluding plant microbial fuel cells, as they use heterotrophs to generate power from substances produced from plants.

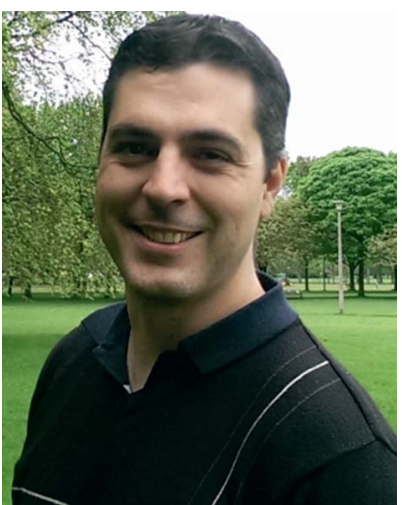

Dr Alistair McCormick holds an MSc from the University of Stellenbosch and a PhD from the University of KwaZulu-Natal, which he gained while at the South African Sugarcane Research Institute. He worked as a postdoctoral fellow at the University of Oxford, University of Cambridge and John Innes Centre before joining the University of Edinburgh in 2013 as a Chancellor's Fellow in plant molecular physiology and synthetic biology. His research interests focus on the biochemistry and physiology of photosynthesis in higher plants and micro-algae.

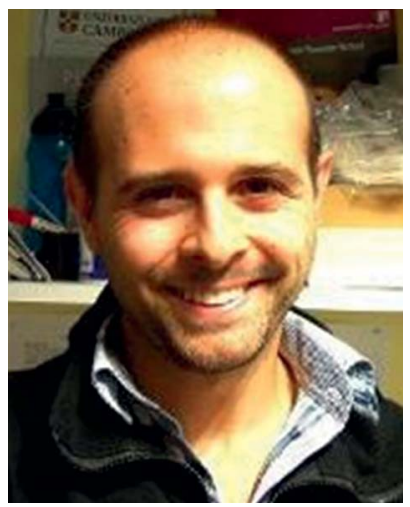

Dr Paolo Bombelli has a multidisciplinary background with specific interests in energy conversion and photosynthesis. He holds an MSc in Plant Biology from the University of Milano-Statale (Italy) and a PhD in Chemical Engineering from the University of Cambridge (UK). His training also includes three years working experience in the fields of biophysics, microbiology and agriculture moving between London, Porto and Florence. Since December 2011 he has been a postdoctoral fellow in the Department of Biochemistry, University of Cambridge with the title of "algal electrician".
The aim of this review is to contextualise recent BPV work in the world of light-harvesting BES research. Firstly, we will summarise the current understanding of microbial electron transfer and exoelectrogenic activity in heterotrophic BESs (Section 2) and then provide a broad review of the present stateof-the-art of light-harvesting BESs and BPV-type systems (Section 3). We will focus primarily on anode-specific configurations i.e. where the phototrophic biological components are localised to and interact with an electron accepting electrode (the anode); and exclude discussion of light-dependent cathodemicrobe interactions (e.g. ref. 17-19), although the latter do represent an area of great emerging potential for using electron accepting microbes to produce fuels (for reviews see ref. 20-22). Thirdly, we will discuss the mechanisms involved in intracellular electron transfer for supplying electron export, and where possible, the putative pathways for mediated and self-mediated electron transfer to the anode (Section 4). We will focus primarily on studies using cyanobacteria, whose function in cellular BPVs has been better characterised than that of other

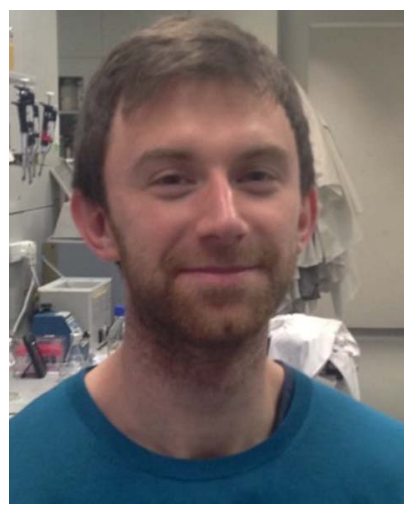

Dr Robert Bradley received his MSci (Hons) from the University of Cambridge in 2009, and remained there to study for his PhD. Research for his doctoral thesis centred on using genetic approaches to gain an understanding of the molecular processes involved in electron export from cyanobacteria, so that export rates might be increased through rational genetic engineering. Since 2013 he has worked as a postdoctoral research associate at Imperial College London, where he is applying a 'synthetic biology' approach to the construction of designer electron export systems and biological decision circuits.

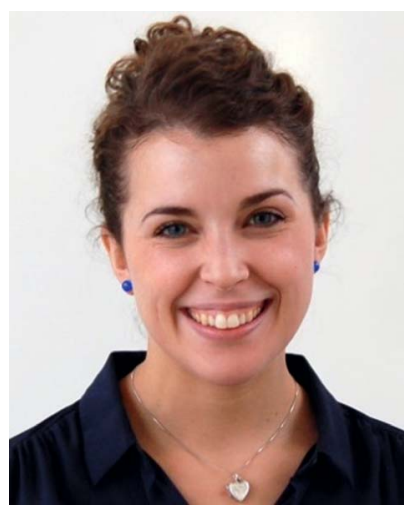

Dr Rebecca Thorne is a researcher at the Norwegian Institute for Air Research (NILU). She studied at the University of Bath to obtain a BSc in Natural Sciences, focussing on biology and environmental science, and a PhD in physical chemistry, developing anodes for algal fuel cells. After working as a postdoc in the Department of Materials Science and Engineering at the Norwegian University of Science and Technology (NTNU), she has worked at NILU since January 2015. Her research activities now include the study of interactions of energy production/industrial activities with environmental pollution/protection. 
organisms. Finally, we will present an estimate of the achievable power outputs of BPV devices (Section 5), and discuss future scientific goals to advance this promising, but as yet relatively underdeveloped technology.

\section{An introduction to microbial electron transfer and microbial fuel cells}

One of the oldest and most commonly studied groups of BESs are microbial fuel cells (MFCs). ${ }^{23}$ In MFCs, living microbes are used to catalyse the oxidation of organic substrates and transfer electrons to an anode, and/or use electrons supplied by a cathode to reduce a substrate (Fig. 2A)..$^{22,24}$ The production of current (i.e. electron flux) is driven by the potential difference between the anodic and cathodic reactions. MFCs using mixed bacterial cultures are typically considered to be more robust than those driven by cultures of single species. ${ }^{25}$ Advantages of the former include higher resistance against process disturbances, higher substrate consumption rates, and the ability to use mixtures of substrates and higher power outputs. Apart from the generation of electrical power, ${ }^{26}$ other more recent BESs using heterotrophic cultures have been designed for waste water detoxification, ${ }^{27,28}$ carbon capture, ${ }^{29}$ water desalination, ${ }^{20,30,31}$ and the reduction of substrates at the cathode surface for fuel production (e.g. hydrogen $\left(\mathrm{H}_{2}\right)$, organic molecules). ${ }^{30,32}$ Clearly the design of a BES will depend on the particular application required.

Analyses of single-species cultures have indicated that a wide selection of microbial families possess endogenous exoelectrogenic activities, including the Alcaligenaceae, Aeromonadaceae, Bacteroidetes, Campylobacteraceae, Clostridiaceae, Desulfuromonadaceae, Enterococcaceae, Geobacteraceae, Pseudomonadaceae, Rhodobacteraceae, Shewanellaceae and Vibrionaceae. ${ }^{\mathbf{1} 33}$ For the dissimilatory Fe(III)-reducing Geobacteraceae (the predominantly characterised group) these processes are primarily a means of extracellular respiration. ${ }^{34,35}$ However, alternative or additional functions have been demonstrated, including cell to cell communication (e.g. quorum sensing), generation of redox stress during pathogenesis, and dissipation or sharing of excess energy within biofilm and/or aggregate communities via interspecies electron transfer., 1,22,35-37

Electrons can reach the anode through indirect extracellular electron transfer (IEET) and/or by direct electron transfer (also known as direct extracellular electron transfer (DEET) $)^{35}$ (Fig. 3). IEET relies on electron carriers that diffuse between cells and the electrode. ${ }^{38}$ Systems that rely on IEET typically suffer from low power densities due to limitations in the rate of mass transport between substrate and electrode (specifically, concentration overpotentials). ${ }^{24}$ Conversely, DEET generally yields higher power densities than IEET-driven systems, but requires close physical contact between cellular components of the electron transfer pathway and the electrode. Cultivation of biofilms directly onto electrode surfaces is critical for effectively exploiting DEET activities ${ }^{39-43}$ and improving our understanding of the factors governing biofilm generation and morphology will be very helpful in this regard.

IEET may occur through the (i) production of fermentative by-products $\left(\text { e.g. } \mathrm{H}_{2}\right)^{44}$ which are subsequently oxidised by the extracellular electron acceptor (e.g. the anode) (Fig. 3A), or (ii) through cycling of redox-active mediator compounds, which can include naturally occurring molecules (e.g. humic substances), ${ }^{45}$ endogenous electron mediators (EEMs) excreted by the organism, or exogenously added artificial electron mediators (AEMs) (Fig. 3B). Various EEMs have been reported for different species, including flavins (Shewanella spp.), phenazines (Pseudomonas spp.) and quinone derivatives (Escherichia coli). ${ }^{\mathbf{4 6 0}}$ Common AEMs used in MFCs (and BPVs) include potassium ferricyanide $\left(\left[\mathrm{Fe}(\mathrm{CN})_{6}\right]^{3-}\right)$, phenazines, phenothiazines, phenoxazines and quinones. ${ }^{51}$ Electron mediator compounds may be lipid-soluble (e.g. phenazines) or lipidinsoluble (e.g. flavins and $\left[\mathrm{Fe}(\mathrm{CN})_{6}\right]^{3-}$ ) (Fig. 4). The advantage of the former is that additional electron transfer components are not required to move reducing equivalents to the outer surface of the organism, though greater control over the rate of electron

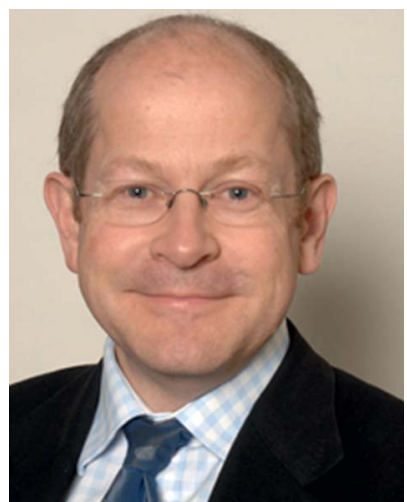

Christopher Howe is Professor of Plant and Microbial Biochemistry in the Department of Biochemistry at the University of Cambridge, and holds a PhD and $S c D$ from Cambridge. His research interests cover a wide range of aspects of photosynthesis. They include the evolution of chloroplasts and chloroplast genomes, the light harvesting and electron transfer reactions underpinning photosynthesis, and - as in this review - the exploitation of photosynthetic organisms for renewable energy production. experimental as well as theoretic-mathematical aspects of biotechnological interfaces, synthetic biology, and microbial material production.

Tobias Wenzel holds physics Universitaet Berlin and the
Unem the Technische J. Craig Venter Institute and is Winton scholar for physics of sustainability. His research focuses on direct electron transfer in biophotovoltaic devices; his broader interests are the 
A

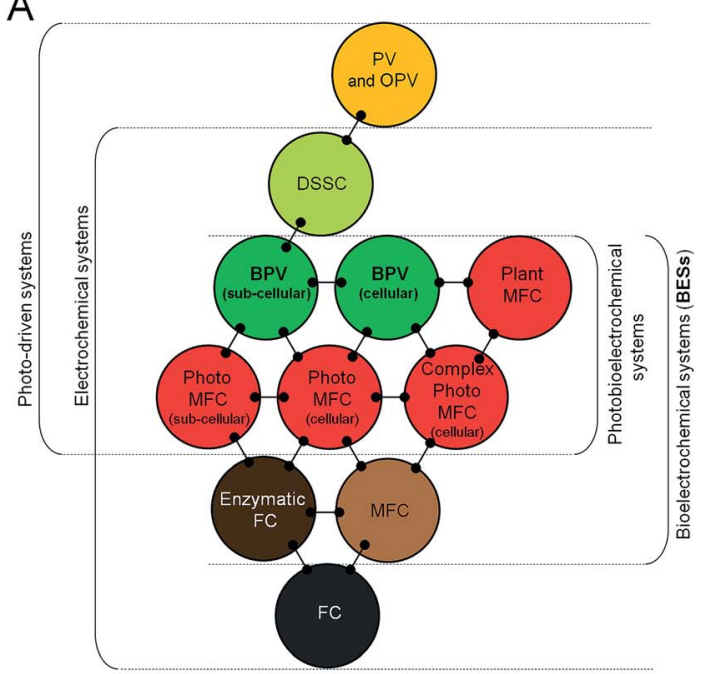

B

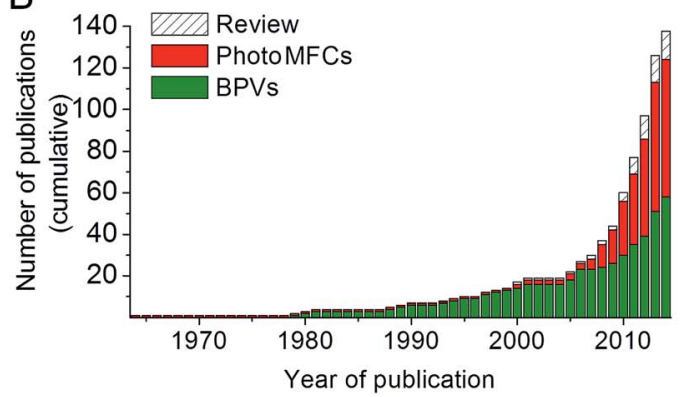

Fig. 1 Biophotovoltaic systems (BPVs) lie at the interface of photovoltaic and bioelectrochemical systems. (A) When at least one of the components catalysing the electrochemical process within fuel cells (FCs) is biologically based (e.g. whole cells, sub-cellular organelles/ membranes and/or enzymes) these systems are defined as bioelectrochemical systems (BESs). Fuel cells (FCs) containing heterotrophic bacteria and fuelled by organic substrates are defined here as microbial fuel cells (MFCs). Similarly, photo-driven systems that generate electrical current directly/indirectly by light energy captured by photoactive biological components, are called biophotovoltaic systems (BPVs) or photoMFCs. Other abbreviations: photovoltaic cell (PV), organic photovoltaic cell (OPV), dye sensitized solar cell (DSSC). (B) Historical overview of BPV and photoMFC studies. Only 37 BPV studies were published from 1964 to 2008 , at rate of 0.82 per year. By contrast, during the last six years 101 articles have appeared in scientific journals, resulting in a 20 -fold increase in the rate of publication (16.8 per year). Data are based on the number of articles mentioning BPVs or synonyms, as defined in this review, in the citation database Web of Science (http://wok.mimas.ac.uk/) since October 2014.

export may be possible with lipid-insoluble mediators. ${ }^{52}$ The cost and potential environmental toxicity of AEMs limits their usefulness in commercial applications, such that AEM-driven MFCs are now considered advantageous only for specific laboratory applications. ${ }^{51}$

DEET relies on microbes forming direct electrical connections with the electrode, either through direct contact with redox proteins on the cell surface (typically c-type cytochromes) ${ }^{53}$ (Fig. 3C) or through extracellular appendages
(Fig. 3D). Geobacter sulfurreducens is well known for using conductive type IV pili to transfer electrons over tens of $\mu \mathrm{m}$ to an insoluble extracellular acceptor (i.e. a metal (hydr)oxide or an electrode) ${ }^{54}$ (Fig. 4), and has produced the highest power densities in pure culture (up to $3.9 \mathrm{~W} \mathrm{~m}^{-2}$ ) of any microbe tested so far. ${ }^{54-56}$ When Geobacter spp. cells grow as a biofilm on a solid electron acceptor they produce an electrically conductive extracellular matrix comprised of pili, exopolysaccharides and outer surface cytochromes. ${ }^{\mathbf{4 3}}$ The formation of a pili network within this matrix is critical for the transfer of electrons from cells within the biofilm that cannot form a direct contact with the electron acceptor surface. ${ }^{40}$ The C-terminal domain of the Geobacter spp. type IV pilin subunit, PilA, contains aromatic amino acid residues which allow metallic-like electron transfer along the length of the pilus through delocalised electron orbitals. ${ }^{\text {57-59 }}$

The mechanism of electron transfer from intracellular oxidation of substrates to the pilus is currently unknown and represents an important area for further work. Outermembrane c-type cytochromes are not essential for conductivity along the pilus but are predicted to be involved in some electron trafficking processes. ${ }^{35,60}$ For example, the hexaheme OmcS has been implicated in mediating electron transfer from pili to $\mathrm{Fe}(\mathrm{III})$ oxides, ${ }^{\mathbf{6 1}}$ and may facilitate electron movement between pilus filaments. ${ }^{37}$ Whilst 'nanowire' extracellular appendages have been observed in other organisms, most notably Shewanella oneidensis MR-1, there is debate as to their composition and whether these structures are used for DEET in vivo ${ }^{\mathbf{3 6 , 6 2}}$ - these observations will be discussed in more detail later in the context of possible exoelectrogenic mechanisms in cyanobacteria. In $S$. oneidensis MR-1, the majority of current has been shown to be transferred via IEET using flavin shuttles. ${ }^{\mathbf{6 3 , 6 4}}$ Nevertheless, $S$. oneidensis MR-1 can also perform DEET via a well-characterised pathway, Mtr, for reducing external metal ions. ${ }^{65,66}$ Electrons are shuttled from the cytoplasmic membrane protein menaquinol oxidase (CymA) to outer-membrane cytochromes (MtrC/OmcA) by the paradigmatic cytochrome:porin pair of MtrA (soluble periplasmic cytochrome) and MtrB (outer-membrane porin). ${ }^{67}$ The cytochrome:porin pattern for electron exchange between an organism and its environment has been identified in several other Gramnegative bacteria, but remains relatively unexplored outside of model species like $S$. oneidensis MR-1. ${ }^{66}$ Recent work has shown $S$. oneidensis MR-1 nanowires are not pili, but extensions of the outer membrane and periplasm that appear to form from chains of outer membrane vesicles. ${ }^{68}$ These membrane extensions contain the outer membrane Mtr components MtrC and OmcA along the surface, an observation that is compatible with the previously proposed multistep redox hopping mechanism of electron transfer along the nanowire. ${ }^{69,70}$ Elucidation of the full extent of the role that these structures play in electron export and inter-cell communication - and how widely distributed these functions are across the bacterial kingdom - is an exciting prospect. In the longer term, heterologous expression to enhance electron transfer in other species may have important applications. 
A Microbial Fuel Cell

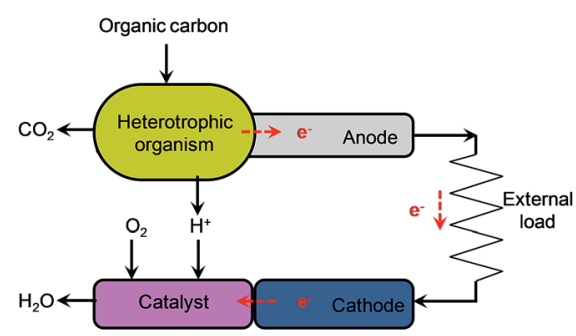

C Complex photosynthetic microbial fuel cell

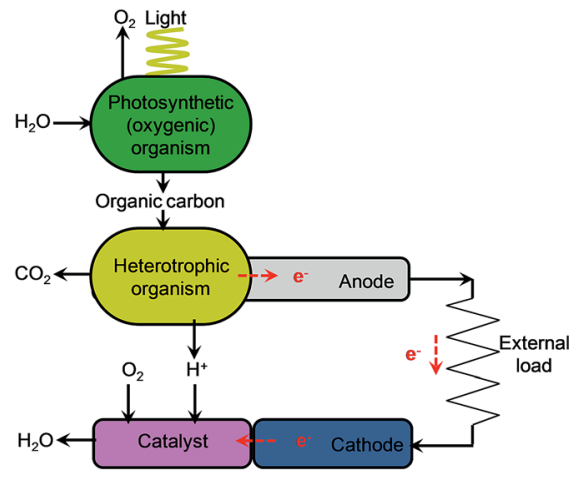

B Photosynthetic Microbial Fuel Cell

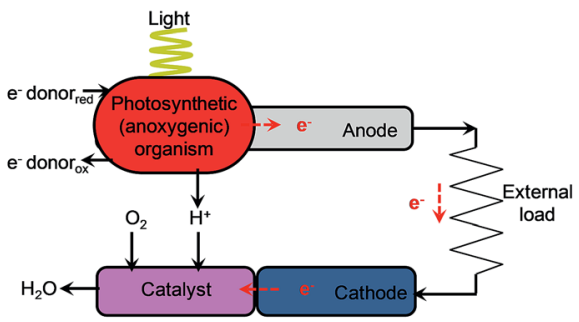

D Biophotovoltaic system

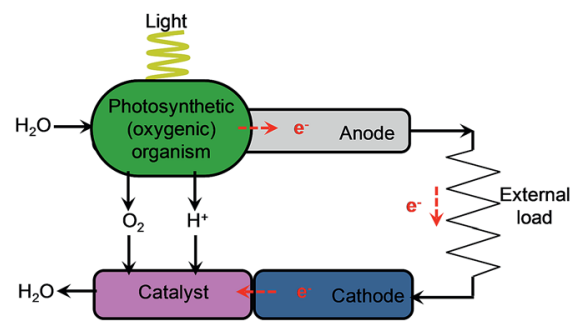

Fig. 2 Illustrative diagrams of bioelectrochemical systems (BESs) and light-dependent BESs. The figure shows the components that lead to electron $\left(\mathrm{e}^{-}\right)$transfer to the anode and the release of protons $\left(\mathrm{H}^{+}\right)$in microbial fuel cells (MFCs) (A), cellular photosynthetic microbial fuel cells (cellular photoMFCs) (B), complex photoMFCs (C) and cellular biophotovoltaic systems (BPVs) (D). In all archetypes a catalyst is shown attached to the cathode that facilitates the terminal electron acceptor reaction (e.g. $\mathrm{O}_{2}+2 \mathrm{H}^{+} \rightarrow \mathrm{H}_{2} \mathrm{O}$ ). For a more detailed illustration of the metabolic components involved in each system see ESI Fig. $1 . \dagger$

\section{BPVs and other light-harvesting BESs}

Having considered possible routes for electron export, we look at systems where photosynthetic organisms are used for current generation (light-harvesting BESs and BPVs) and highlight the best performances to date for each (Fig. 5; ESI Table $1 \dagger$ ). Where possible, results have been presented in power output per anode area or volume at the current density achieved. True BPVs use only oxygenic photosynthetic organisms (or fractions thereof) to capture light, carry out charge separation of water and supply some of the resulting electrons to an anode via IEET (with AEMs or EEMS) or DEET. ${ }^{71}$ We distinguish BPVs from other light-harvesting BESs that may or may not split water, but rely on an exogenous supply of reducing equivalents. Previously the latter category of BESs have been referred to as photosynthetic microbial fuel cells (photoMFCs). ${ }^{51}$ BPVs can also be differentiated from systems that utilise oxygenic photosynthetic organisms (such as algae or vascular plants) that harvest light energy but are subsequently used only as a feed stock or a source of organic fuels (e.g. plant MFCs). ${ }^{16,72}$ Below we have divided our discussion of photoMFCs into three sub-categories - those that use (i) sub-cellular components or (ii) living microbes to drive current production directly, and those that use (iii) a mixture of living photosynthetic and heterotrophic species (complex photoMFCs). There are further examples of systems that utilize biologically derived pigments to harvest light (e.g. chlorophyll, carotenoids). Such systems are more similar to dye-sensitized solar cells (DSSCs) or organic photovoltaic cells (OPVs) $)^{73,74}$ and will not be discussed here. It is important to recognize that, unless water is the ultimate source of electrons, as with oxygenic photosynthetic systems, a sacrificial electron donor is required, a requirement that is likely to impose limitations on large-scale exploitation.

For BPVs the biological components used to harvest light energy range in complexity, from purified protein complexes (sub-cellular BPVs) to whole cells. In principle, the initial process involved in the generation of electrons is common to all BPV systems, and relates to the use of an oxygenic photosynthetic reaction centre (e.g. photosystem II (PSII)) where electrons are generated by the light-driven oxidation of water. ${ }^{75}$ The pathway(s) of electron flow from PSII to the external circuit is then dictated by the type of biological material(s) used. Below we have divided BPVs into two sub-categories based on systems that utilise sub-cellular components or whole cells.

\section{Sub-cellular photoMFCs}

The most fundamental examples of photoMFCs systems are those that utilise purified, non-oxygenic photosystem components directly attached to the surface of an electron acceptor. ${ }^{76,77}$ One of the earliest studies utilised the bacterial photosynthetic reaction-centre of the purple nonsulfur (PNS) species Rhodobacter sphaeroides. ${ }^{78}$ When dried as a thin film onto a $\mathrm{SnO}_{2}$ electrode, the reaction-centre complexes were able to perform 
A

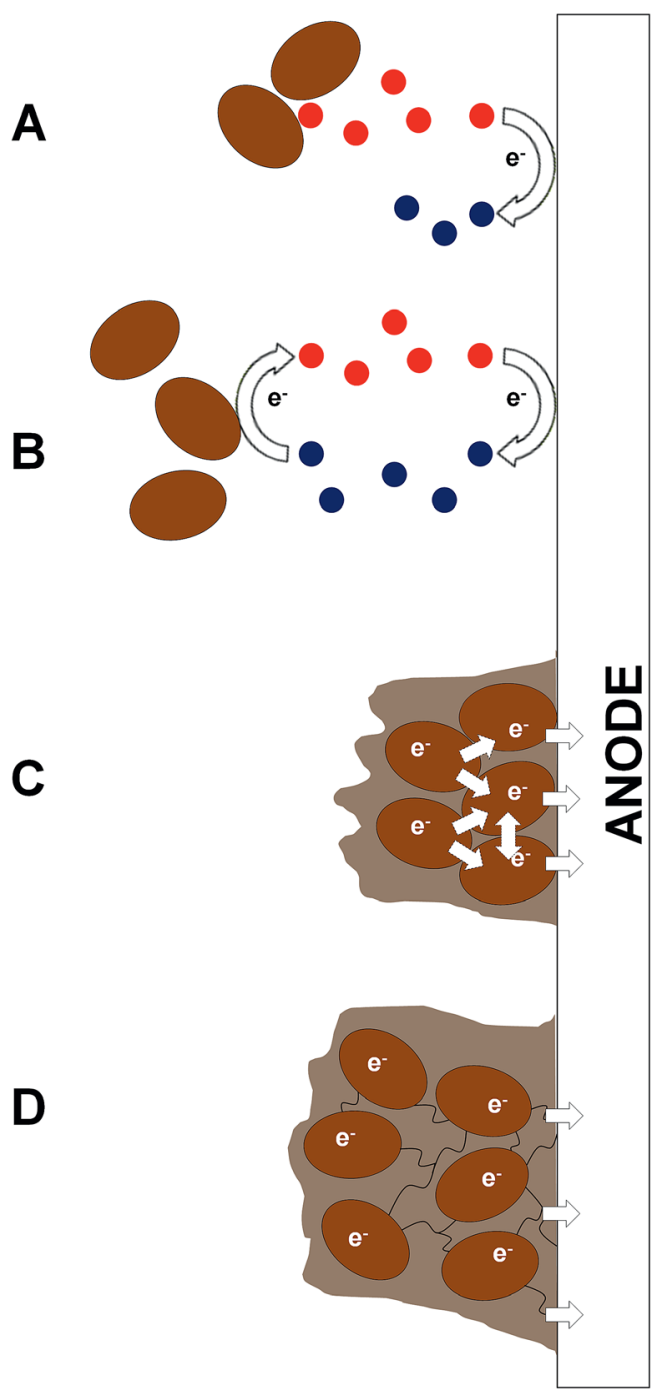

Fig. 3 Mechanisms of microbial electron transfer in bioelectrochemical systems (BESs). The basic mechanisms for extracellular electron transfer to the anode are either indirect (IEET) or direct (DEET). These include (A) oxidation of end products/metabolites (e.g. $\mathrm{H}_{2}$ ) without recycling (IEET); (B) cycling of endogenous electron mediators (EEMs), or artificial electron mediators (AEMS) (IEET); (C) direct contact and electron transfer by surface redox proteins (typically from cells in a biofilm) (DEET); and (D) direct contact by nanowire appendages between cells in a biofilm resulting in a nanowire web that transfers electrons along other nanowires, to neighbouring cells or to the electrode (DEET). Depending on the species or consortium used, all four mechanisms may exist in a single BES.

light-induced charge separation, resulting in photocurrents of ca. $3 \mathrm{~mA} \mathrm{~m}^{-2}$.

More recent work has led to significant advances in our fundamental understanding of the photosystem kinetics of oxygenic reaction centres. When PSI isolated from Synechococcus elongatus (formerly named Anacystis nidulans) was anchored to a gold surface acting as an electrode, red laser light could be used to trigger a series of redox reactions in which electrons were transferred directly from the photosystem to the electrode. ${ }^{\mathbf{1 0}}$ Gerster et $a l .{ }^{10}$ estimated that the photocurrent

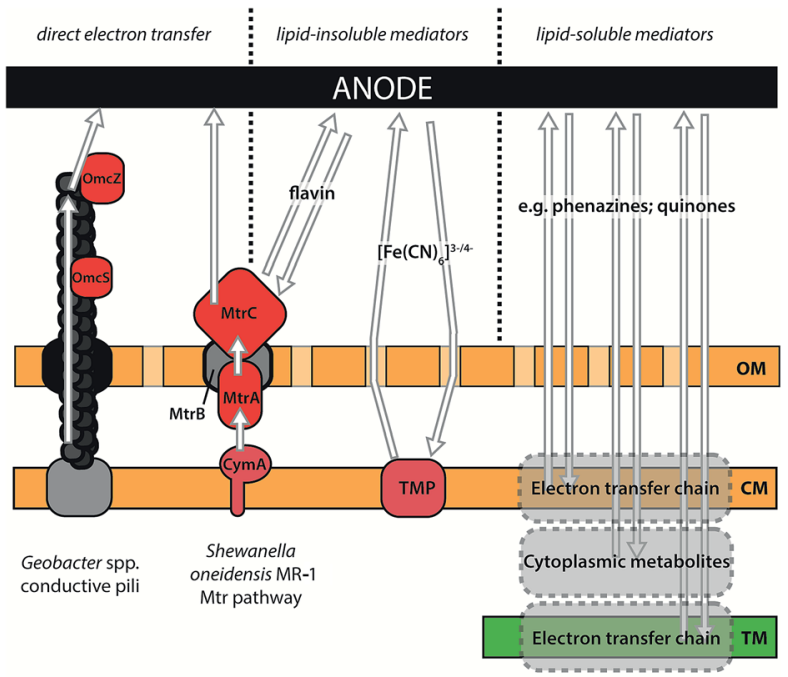

Fig. 4 Illustration of components involved in IEET and DEET in exoelectrogenic species. DEET between organism and electrode has been observed in Geobacter spp., which use conductive type IV pili to transfer electrons over long distances, and in Shewanella oneidensis MR-1, which transfers electrons to insoluble acceptors using outer membrane cytochromes. See text for details of the proteins involved. Indirect (mediated) electron transfer can occur via lipid-insoluble mediators that must be reduced by proteins on or external to the cytoplasmic membrane, or by lipid-soluble mediators that can oxidise substrates within lipid bilayers or in the cytoplasm. Mediators may be naturally produced by an organism (e.g. flavins from S. oneidensis MR1; phenazines from Pseudomonas spp.) or added exogenously (e.g. ferricyanide $\left(\left[\mathrm{Fe}(\mathrm{CN})_{6}\right]^{3-}\right.$ which might accept electrons from redoxactive transmembrane proteins (TMP)). OM: outer membrane; CM: cytoplasmic membrane; TM: thylakoid membrane.

generated by a single illuminated PSI complex under dry state conditions corresponded to a remarkable $1500 \mathrm{~mA} \mathrm{~m}^{-2}$. These studies show that individual photosystem complexes can act as light-driven, electron pumps and may be useful as current generators in nanoscale electric circuits, which is an exciting future prospect. However, given the energy cost in producing the complexes, it seems unlikely they will have a role in largescale power generation.

\section{Cellular photoMFCs}

PhotoMFCs use living chemoautotrophic microbes (typically PNS species) to generate electricity under anaerobic conditions in a light-dependent manner (Fig. 2B). The microbes in these systems do not contain a PSII-type reaction centre and thus require an exogenous supply of reducing equivalents to grow and function. Similar to cellular BPVs (below), photoMFCs use living cells and are therefore significantly more robust than systems that use sub-cellular photosynthetic fractions. Whole cells are relatively far more resilient, capable of self-repair and reproduction, and can produce current under both light and dark conditions. PhotoMFCs presently hold the record for the highest light-driven current outputs achieved using an intact photosynthetic organism (Fig. 5; ESI Table $1 \dagger$ ). 
A
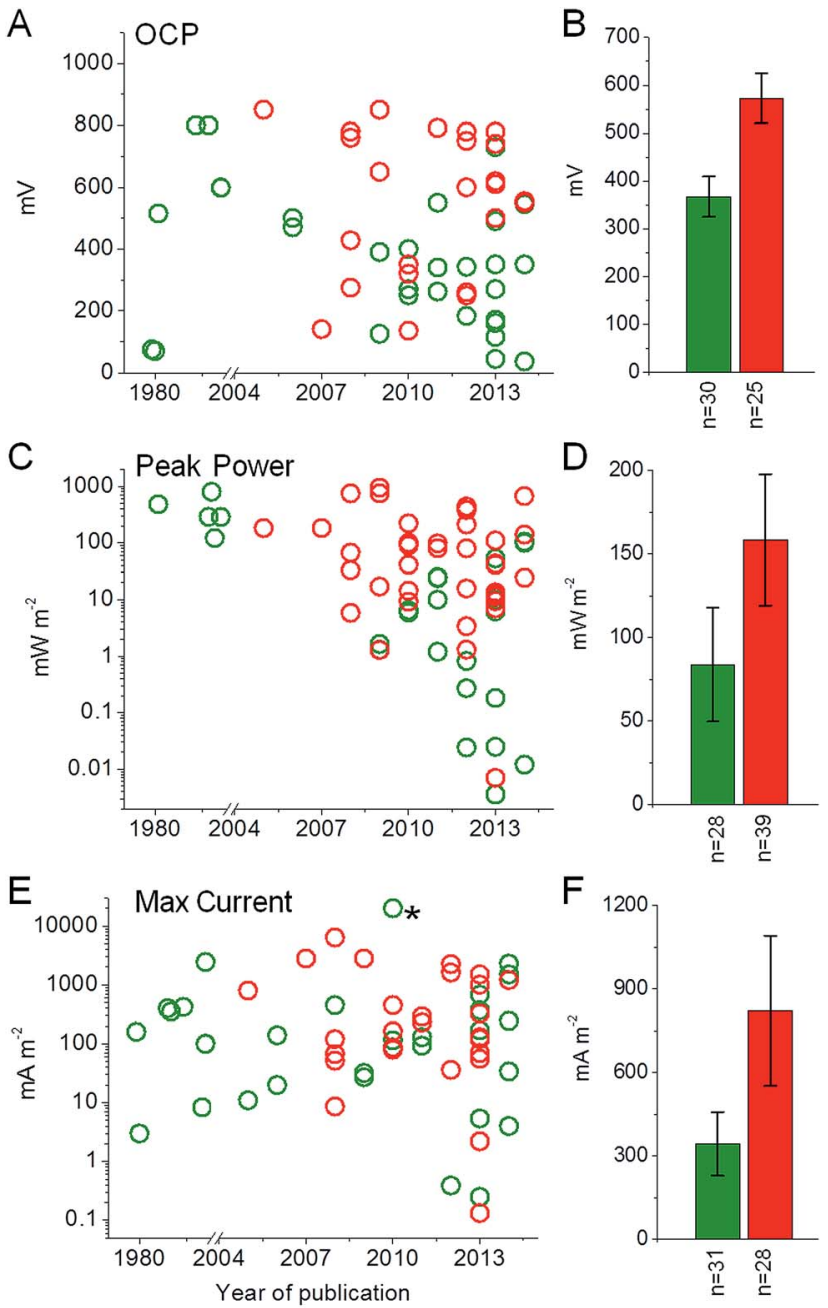

PhotoMFCs BPVs (at $800 \mathrm{~mA} \mathrm{~m}^{-2}$ ) and a light conversion (to electrical charge) efficiency of $8.5 \%$ from the fuel cell (i.e. not taking into account the growth efficiency of the supplied organic feedstock). The latter result was remarkable as the achieved conversion of $10 \%$ of the solar energy into chemical energy in $\mathrm{H}_{2}$ is considered maximal for photobiological $\mathrm{H}_{2}$ production. ${ }^{80}$ Further optimisations have led to some of the highest BES currents measured using axenic $R$. sphaeroides cultures, with maximum outputs of $790 \mathrm{~mW} \mathrm{~m}^{-2}$ under light conditions, but only $0.5 \mathrm{~mW} \mathrm{~m}^{-2}$ in the dark. ${ }^{81}$ Notably, R. sphaeroides does not appear to form anodic biofilms, indicating that power outputs were primarily IEET-dependent.

More recently, the metabolically versatile PNS species Rhodopseudomonas palustris was shown to be able to metabolise a feedstock consisting of intact filamentous cyanobacteria (Arthrospira maxima) while producing current outputs of 5.9 $\mathrm{mW} \mathrm{m} \mathrm{m}^{-3}\left(27.9 \mathrm{~mA} \mathrm{~m}^{-3}\right) .^{6}$ Notably, both cyanobacterial growth and thus ultimately $R h$. palustris power outputs were driven only by light. Such systems exist at the borders of what might be considered a complex photoMFC (see below). Rh. palustris was also the first PNS for which the ability to perform DEET following biofilm growth on the anodic electrode was demonstrated. ${ }^{\mathbf{8 2}, 83}$ In those systems, $\mathrm{H}_{2}$ could be excluded from contributing to electron transfer as non-metal anodic materials were used (e.g. carbon paper, graphite brushes or polyaniline microparticles). Furthermore, Morishima et $a .^{82}$ utilised a mutant strain of $R h$. palustris with deletions in the genes necessary for $\mathrm{H}_{2}$ production. The complete genome sequence of Rh. palustris indicates an abundance of potential electron export mechanisms, ${ }^{84}$ such as the MtrA/MtrB cytochrome: porin homologues MtoA/MtoB. There is currently limited understanding of the molecular components involved in this possibly unique electron transfer mechanism, but improving our understanding of it, together with the development of improved genetic tools, is likely to enhance considerably the possibilities for exploiting this versatile organism.

There are several further examples of systems that do not rely on PNS species for generating current that can still be defined as photoMFCs. Genetic manipulation of $S$. oneidensis MR-1 modified to express proteorhodopsin, a light-driven proton pump, resulted in cells with increased nutrient uptake rates in the light. ${ }^{85}$ When the cultures were inoculated into an MFC setup, Johnson et al. ${ }^{85}$ showed significant increases in current outputs following illumination. The light-dependent increase in current was proportional to the intensity of the light used and, depending on the age and thickness of the anodic biofilm, was up to 2.5 -fold higher than respiratory current outputs in the dark. Rosenbaum et al. ${ }^{\mathbf{4 4}}$ demonstrated a non-PNS system using a green algal species (Chlamydomonas reinhardtii) maintained in an acetate-supplemented feedstock. By inhibiting the oxygen evolving complex (OEC) activity of PSII in C. reinhardtii through sulphur deprivation, $\mathrm{O}_{2}$ can be depleted from the culture by reducing the photosynthetic $\mathrm{O}_{2}$ production rate below the rate of mitochondrial respiration. Under anaerobic conditions the native hydrogenase activities are not inhibited and $C$. reinhardtii is able to perform light-dependent $\mathrm{H}_{2}$ evolution over a period of several days. ${ }^{86}$ Rosenbaum et al. ${ }^{44}$ exploited this phenomenon to produce electricity using a conductive polymer-coated platinum 
electrode, resulting in a maximum power output of $7 \mathrm{~mW} \mathrm{~L}^{-1}$ (at $30 \mathrm{~mA} \mathrm{~L}^{-1}$ (i.e. per litre of liquid culture)).

\section{Complex photoMFCs}

Complex PhotoMFCs comprise a broad variety of different kinds of light-harvesting BESs that contain both living heterotrophic and autotrophic species (Fig. 2C). These include devices (i) based on soil sediments, ${ }^{27,87,88}$ (ii) with anodic liquid-culture consortia, ${ }^{7,89-93}$ (iii) with phototrophic biocathodes ${ }^{94,95}$ and (iv) that utilise rhizosphere-based heterotrophic microbes nourished with higher plant root exudates (plant MFCs). ${ }^{\mathbf{1 6 , 8 8 , 9 6 , 9 7}}$ BESs that do not contain living autotrophic species within the cell setup, for example MFCs fed with algal-based substrates, are excluded from this definition of complex photoMFCs. ${ }^{72,98}$

Complex photoMFCs (and plant MFCs) are widely studied from an electrochemical and ecological perspective, and have been reviewed recently (see ref. 8 and 9). Although they are typically mediatorless and require moderately low maintenance, complex photoMFCs are highly difficult to characterise in terms of the molecular biological factors contributing to power outputs. This stems from (i) the use of a microbial consortium at the anode and/or (ii) the use of effluent feedstocks that are likely to be variable or poorly characterised. Recent evidence indicates some higher plants (e.g. Lemna spp.) may also exude EEM equivalents, ${ }^{99}$ which further escalates the potential complexity in plant MFCs. Complex photoMFCs are challenging to optimise and replicate experimentally, and often it takes weeks for the exoelectrogenic microbial populations to develop. Nevertheless, due to ease of setup, these systems can readily be integrated into other renewable bio-processes, including anaerobic digestion, biomass production and plant agriculture (e.g. constructed wetlands, planted recreational areas and field crops).97,100,101 To date, the highest power outputs reported are from a sediment-type system inoculated with the green alga Chlorella vulgaris and electrochemically active bacteria sourced from waste waters $\left(68 \mathrm{~mW} \mathrm{~m}{ }^{-2}\right) \cdot{ }^{27}$ For plant MFCs, Wetser et al. ${ }^{102}$ recently achieved maximum power outputs of $679 \mathrm{~mW} \mathrm{~m}{ }^{-2}$ plant growth area, with an average output over two weeks of $240 \mathrm{~mW} \mathrm{~m}^{-2}$ (ESI Table $1 \dagger$ ). Although good progress has been made towards increasing the long term sustainability of these systems, overall percentage conversion of light into electrical energy remains low $(c a .0 .5 \%) .{ }^{102}$ Power outputs appear to be limited by substrate availability at the anode (i.e. plant root exudates), so improved system design and/ or selection of plant species with increased rates of rhizodeposition is likely to increase power outputs. Further identification of specific syntrophic processes within the bacterial communities characteristic of exoelectrogenic anodic biofilms also should help to improve the performance of these systems. ${ }^{103}$

\section{Sub-cellular BPVs}

Similar to sub-cellular photoMFCs that utilise the bacterial photosynthetic reaction-centre or PSI, the most fundamental examples of sub-cellular BPV systems are those that use components of the oxygenic PSII photosystem complex. ${ }^{76}$ Several studies have utilised PSII from the thermophilic cyanobacterium Thermosynechococcus elongatus, as it is structurally well characterised and highly stable in its purified form. ${ }^{76,104}$ When $T$. elongatus PSII was fixed to a modified indium tin oxide (ITO) anode in the appropriate orientation, electrons gained by light and water photolysis in the OEC of PSII could flow directly to the nearby quinone- $\mathrm{Q}_{A}$ or quinone- $\mathrm{Q}_{B}$ sites, and then to the circuit. ${ }^{104}$ The water-oxidising biophotoanode resulted in currents of $16 \mathrm{~mA} \mathrm{~m}^{-2}$ and could be correlated to an oxygen $\left(\mathrm{O}_{2}\right)$ evolution rate of approximately 0.18 $(\mathrm{mol} \mathrm{O})(\mathrm{mol} \mathrm{PSII})^{-1} \mathrm{~s}^{-1}$.

When more complex sub-chloroplastic photoactive components, such as thylakoid membranes, are used, electrons generated at the OEC of PSII can move through the linear photosynthetic electron transport chain (PETC) ${ }^{75}$ to the reductive end of PSI. Ryu et al. ${ }^{105}$ demonstrated the impressive capability of thylakoid membranes to produce a photocurrent in vivo. Following the insertion of nanoelectrodes into chloroplasts of living C. reinhardtii cells, photocurrents of up to up to $20 \mathrm{~A} \mathrm{~m}^{-2}$ (based on cell area) were observed, ${ }^{105}$ although scaleup of this approach would clearly be difficult. In most studies, suspensions of thylakoid membranes are isolated from living tissues (typically from spinach leaves) and current is generated via IEET. ${ }^{12,13,106,107}$ As the process of membrane purification washes away endogenous soluble electron carriers (e.g., ferredoxin, $\mathrm{NADP}^{+}$), the addition of AEMs is required for more efficient shuttling of electrons from PSI to the anode. Calkins et al. ${ }^{12}$ recently reported the highest power outputs yet achieved with spinach thylakoids of $53 \mathrm{~mW} \mathrm{~m}^{-2}$ (at $250 \mathrm{~mA} \mathrm{~m}^{-2}$ ) following immobilization of thylakoids onto multi-walled carbon nanotubes. Although the nanotube-thylakoid composites exhibited direct electron transfer, current outputs were significantly enhanced by the addition of an AEM.

Sub-cellular BPVs have several important applications, particularly with regards to the study of the fundamental biological components and characteristics of BPV systems. However, the practical applications for sub-cellular BPV systems are limited by the stability of light harvesting complexes ex vivo. The PSII reaction centre is a primary target of photooxidative damage, which can be repaired in vivo (see ref. 108). Suspensions of thylakoid membranes have been reported to work for a maximum of 30-40 min followed by a rapid loss of activity. ${ }^{13}$ Following isolation, whole chloroplasts typically also lose their photosynthetic capacity within a few hours. However, isolated chloroplasts from the algae Vaucheria litorea in symbiotic association with the sea slug Elysia chlorotica have been reported to remain functional for over nine months. ${ }^{109}$ Nevertheless, this longevity has not been achieved in BES experimental systems. Without the ability to self-repair, large scale application of sub-cellular BPVs remains a challenge.

\section{Cellular BPVs}

In cellular BPVs, living oxygenic photosynthetic microbes are used to generate current through the photolysis of water, and supply it to an electrode without the aid of heterotrophic species (Fig. 2D). Notably, microbes in cellular BPVs can also generate current in the dark via the respiratory breakdown of internal 
carbon reserves accrued during the light, and are capable of producing power throughout a diurnal period. ${ }^{13,15}$ Historically the use of prokaryotic cyanobacterial species has been favoured in cellular BPVs over more complex eukaryotes, such as green algae. As whole organisms, cyanobacteria are robust compared to sub-cellular photosynthetic fractions, whilst their relatively simpler physiology compared to eukaryotes (e.g. fewer transmembrane electron transfer steps required) ${ }^{110}$ and lower basal energy requirements may make them more efficient for light transduction.

Early studies demonstrating light-dependent current using cyanobacteria in the anodic compartment utilised various different species, including filamentous (Phormidium spp., Anabaena spp.). ) $^{111-114}$ and unicellular (Synechococcus spp., Synechocystis spp. $)^{115-120}$ strains. To date, power outputs higher than a few $\mathrm{mW}$ have been achieved only by using lipid-soluble AEMs to extract electrons from within the microbe (e.g. $288 \mathrm{~mW} \mathrm{~m}^{-2}$ (at $\left.600 \mathrm{~mA} \mathrm{~m}^{-2}\right)^{117}$ ). These include compounds such as hydroxy1,4-naphthoquinone (HNQ), ${ }^{112,113,116-118}$ 2,6-dimethyl-1,4-benzoquinone (DMBQ), ${ }^{119,120}$ diaminodurene (DAD) ${ }^{115,120}$ and methylene blue. ${ }^{114}$ Although lipid-soluble AEMs are effective at increasing currents, their addition can lead to a significant reduction in microbe viability over time. ${ }^{115}$ Lipid-soluble AEM toxicity may not necessarily be a result of over depletion of intracellular cell reserves, but could be linked to more complex intracellular signalling processes. ${ }^{121}$ Alternatively non-lipid AEMs, such as $\left[\mathrm{Fe}(\mathrm{CN})_{6}\right]^{3-}$, have been used with good success to reduce these potential toxic side effects ${ }^{13,122,123}$ (Fig. 3). To date, the maximum power output reported for an AEM cellular BPV system using $\left[\mathrm{Fe}(\mathrm{CN})_{6}\right]^{3-}$ is $24 \mathrm{~mW} \mathrm{~m}^{-2} .{ }^{122}$

More recently there has been renewed interest in cellular BPVs that produce current in the absence of AEMs, a feature which would clearly be desirable for enhancing the sustainability of BPVs. Zou et al. ${ }^{124}$ was one of the first groups to show a small positive light response in a mediatorless BPV with Synechocystis sp. PCC 6803 (hereafter Synechocystis) following biofilm growth on a carbon-based electrode. This study was followed by an in-depth screening of several cyanobacterial species that showed light-dependent exoelectrogenic activities are common across a wide selection of oxygenic photosynthetic microbes. ${ }^{125}$ Although the conversion rate of light into electrical power was generally low (ranging from $0.05-0.3 \%$ ), Pisciotta et al. ${ }^{125}$ achieved a maximum power output of $6 \mathrm{~mW} \mathrm{~m}^{-2}$ and showed that a positive light response could be maintained for several weeks. Further work has demonstrated that outputs vary considerably depending on species, light intensity, wavelength, temperature and the anodic material used., ${ }^{6,14,15,126,127} \mathrm{~A}$ wide variety of eukaryotic algae have now also been shown to respond positively to light in mediatorless BPVs. ${ }^{15,128-130}$ Increased power outputs have also been observed using BPV stacking approaches. ${ }^{15,131}$ A microfluidic-based BPV has recently demonstrated the highest recorded maximum power densities of $100 \mathrm{~mW} \mathrm{~m}^{-2}$ in the light $\left(80 \mathrm{~mW} \mathrm{~m}{ }^{-2}\right.$ in the dark). ${ }^{132}$

It has been postulated that $\mathrm{O}_{2}$ produced during photosynthesis is a limiting factor for power outputs in all BPVs. $\mathrm{O}_{2}$ reacts readily with electrons to form radicals and could therefore compete with anodic electron transfer and increase anodic potentials. However, the full extent to which $\mathrm{O}_{2}$ affects power outputs in mediatorless BPVs (and MFCs) is still unclear and not well studied. ${ }^{133}$ It has also been suggested that photosynthetic $\mathrm{O}_{2}$ production may enhance cathodic potentials. For example, when photosynthetic biofilms are grown on the cathode (e.g. in complex photoMFCs) increased current outputs have been observed in the light. ${ }^{94,95}$ However, even in a singlechamber mediatorless BPV the rate of $\mathrm{O}_{2}$ diffusion towards the cathode was shown to be too slow to account for the observed light-dependent increases in power outputs observed. ${ }^{15}$ Thus the increase in power in the light must originate from anodic interactions, rather than an effect on the cathode.

Although the vast majority of mediatorless BPV studies to date have demonstrated increased power outputs in the light, two studies using filamentous cyanobacterial species have shown a negative response to illumination..$^{134,135} \mathrm{Fu}$ et al. ${ }^{134}$ showed roughly 10 -fold higher power outputs in the dark compared to the light $\left(1.64 \mathrm{~mW} \mathrm{~m}^{-2} v s .0 .132 \mathrm{~mW} \mathrm{~m}^{-2}\right)$ with Spirulina platenis biofilms. The negative response to light persisted under a wide variety of operating conditions (e.g. differences in $\mathrm{pH}$, temperature and electrode spacing) and was rationalised by the inhibitory effects of photosynthetic $\mathrm{O}_{2}$ production on anode performance. ${ }^{135}$ However, a recent study with a mediatorless BPV using a similar filamentous species (Arthrospira maxima) not only showed a positive light response, but further demonstrated that increased light resulted in increased power output. ${ }^{136}$ It is unclear why these studies produced conflicting results, but a possible explanation may be due to the different anodic materials used by Fu et al. (platinum) $)^{134,135}$ and Inglesby et al. (indium tin oxide). ${ }^{136}$ Platinum electrodes are not well suited to single chamber BESs due to the increased likelihood of interactions with organic compounds and $\mathrm{O}_{2}$, resulting in mixed potentials and the flow of internal currents. ${ }^{137}$ Nevertheless, there remains a crucial need to develop a deeper understanding of the molecular mechanisms involved in microbe-electrode interactions for oxygenic photosynthetic microbes.

The capacity for electron transfer from oxygenic photosynthetic microbes to an electrode remains very low when compared with MFCs and photoMFCs. Current generated by substrate oxidation over the total number of electrons available in the substrate (e.g. acetate) has been reported to be near $100 \%$ for G. sulfurreducens in MFCs and $40-50 \%$ for Rh. palustris in photoMFCs. ${ }^{55,83}$ In comparison, current produced by oxygenic photosynthetic microbes in BPVs, which use $\mathrm{H}_{2} \mathrm{O}$ as a substrate, was calculated to be less than $0.5 \%$ of the total number of electrons generated by water oxidation on the basis of data reported for Phormidium spp. ${ }^{111}$ If BPVs of the future are to function (i) without AEMs and (ii) produce useful power outputs, then the natural electron export processes must be understood and improved. ${ }^{71}$

We will now consider electron export processes in BPVs. The discussion will be limited to cyanobacteria, which are currently the most well characterised microbes in cellular BPV systems. We will summarise what is known about the intracellular electron transfer pathways in cyanobacteria that contribute to unassisted exoelectrogenic activity, and discuss possible 
mechanisms of electron export from the organism to extracellular acceptor.

\section{The molecular basis of exoelectrogenic activity in cyanobacteria}

Cyanobacteria have a Gram-negative structure of cytoplasmic membrane, cell wall, and outer membrane, plus (with the exception of Gloeobacter) multiple thylakoid membranes stacked in the cytoplasm. ${ }^{138}$ In cyanobacteria, the thylakoid membranes are the main site of energy production, containing both photosynthetic and respiratory electron transfer chain components, whilst the cytoplasmic membrane contains an abbreviated respiratory electron transfer chain. ${ }^{110}$ Whilst proteins can probably be trafficked between the thylakoid and cytoplasmic membrane systems, ${ }^{139}$ the overall connectivity of the two is very limited; ${ }^{140}$ consequently the plastoquinone pools in each system are widely regarded as being distinct from one another. Fig. 6 shows the consensus opinion of the distribution of electron transfer components within the membranes of Synechocystis. ${ }^{110}$ It is clear that cyanobacteria have an electron

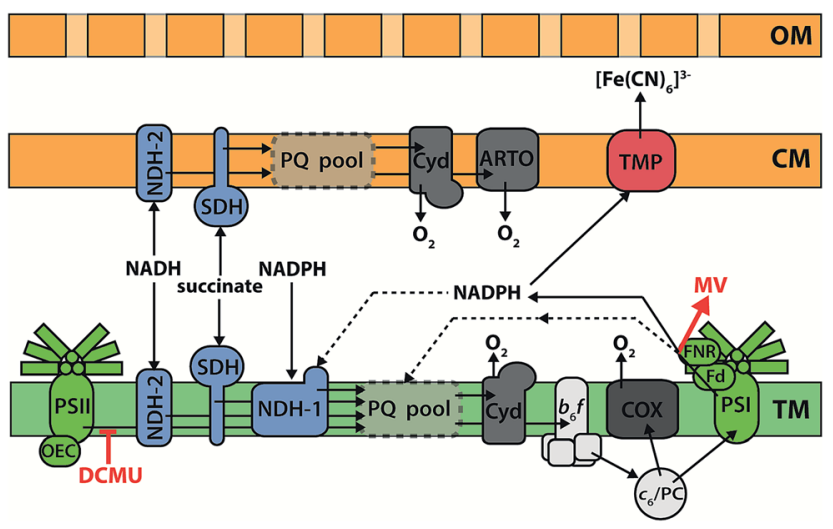

Fig. 6 Electron transfer components in Synechocystis sp. PCC 6803 The plastoquinone (PQ) pool in the thylakoid membrane (TM) can be reduced by respiratory inputs (NADPH:plastoquinone oxidoreductase $(\mathrm{NDH}-1), \mathrm{NADH}$ :plastoquinone oxidoreductase (NDH-2), and succinate:plastoquinone oxidoreductase (SDH)) and by oxidation of water via the oxygen evolving complex (OEC) and photosystem II (PSII). When photosystem I (PSI) is provided with light, electrons may exit the $\mathrm{PQ}$ pool via the cytochrome $b_{6} f$ complex $\left(b_{6} f\right)$, cytochrome $c_{6}$ /plastocyanin $\left(c_{6} / P C\right)$, and PSI to ferredoxin (Fd) and NADPH via the ferredoxin:NADPH oxidoreductase (FNR). Cyclic electron flow around PSI is possible. Respiratory electron flow from the $P Q$ pool to oxygen occurs through the cytochrome bd quinol oxidase (Cyd), or through the cytochrome-c oxidase (COX) via the $b_{6} f$-complex and $c_{6} / P C$. The flavodiiron complexes Flv1/3 and Flv2/4 (not shown) also act as electron sinks, protecting PSI and PSII respectively from photodamage. The cytoplasmic membrane (CM) contains a truncated respiratory electron transfer pathway; the alternative respiratory terminal oxidase (ARTO) is exclusively located in the CM. Ferricyanide $\left(\left[\mathrm{Fe}(\mathrm{CN})_{6}\right]^{3-}\right)$ can diffuse through the porous outer membrane $(O M)$, and reduction is hypothesised to occur via an unidentified transmembrane protein (TMP) located in the cytoplasmic membrane. The sites of action of the electron transfer inhibitors DCMU and methyl viologen (MV) are indicated in red. transfer network that is adapted for light harvesting, but not for exoelectrogenesis. The photosynthetic machinery is located in internal membranes that can be stacked to maximize the light harvesting capacity of the cell, but this separates electron generation from electron export. In addition, many terminal electron sinks exist to protect the organism against high light and reductive stress. For example, the Flv2/4 system can oxidize PSII, ${ }^{14,142}$ and the respiratory terminal oxidase complexes can be used to oxidize the plastoquinone pool. ${ }^{143-145}$ With respect to exoelectrogenic activity, however, these pathways can be considered as wasteful alternatives to electron export. ${ }^{146}$

\section{Electron transfer inhibitors}

Understanding which intracellular electron transfer pathways in cyanobacteria supply reducing equivalents for exoelectrogenic activity would greatly facilitate attempts at improving the current production from these organisms. The classic method of probing electron transfer pathways is to prevent reduction/ oxidation at a certain point, either using a chemical inhibitor to block or divert electron transfer, or by genetically manipulating the organism to remove a component of the pathway.

Early inhibitor investigations of cellular BPV systems demonstrated that when a current increase was observed upon illumination, this was mainly due to the activation of water photolysis at PSII, rather than photo-stimulation of another metabolic process feeding into exoelectrogenesis. The quinone analogue DCMU (3-(3,4-dichlorophenyl)-1,1-dimethylurea) prevents oxidation of PSII by plastoquinone, ${ }^{147}$ and addition of DCMU was shown to reduce drastically the photocurrent in a number of studies. ${ }^{111,113,119}$ However, because most of these early studies used lipid-soluble AEMs to extract current from the cyanobacteria, they can only reveal the route electrons take from PSII to the point of mediator reduction.

A handful of studies have used chemical inhibitors to interrogate the intracellular electron transfer pathways that supply electrons to the outside of the cyanobacterial cytoplasmic membrane. Unfortunately, specific experimental conditions varied between all of these studies, but the results generally indicate that electrons generated by PSII that are destined for export leave the PETC at PSI. It may be noted that this model is consistent with the plastoquinone pools in the thylakoid and cytoplasmic membranes being separate; photosynthetic electrons must be transferred across the cytoplasm in order to reach the cytoplasmic membrane and be exported. If the plastoquinone pools were connected, they could provide a route for transfer of photosynthetic electrons from the thylakoid to the cytoplasmic membrane.

Experiments by Bombelli et al. ${ }^{13}$ used $\left[\mathrm{Fe}(\mathrm{CN})_{6}\right]^{3-}\left(E_{\mathrm{m}}=430\right.$ $\mathrm{mV}$ at $\mathrm{pH} 7$ ) as a lipid-insoluble AEM, the reduction of which can be followed electrochemically or spectroscopically. They observed that the light-stimulated increase in current output from Synechocystis was severely diminished when DCMU was added, showing that water photolysis is the source of the exported electrons. This conclusion is supported by more recent work from Cereda et al. ${ }^{126}$ who used a mutant strain of Synechocystis lacking a functional PSII to show that the majority of 
photocurrent was derived from water. In the experiments of Bombelli et al., ${ }^{13}$ a residual light effect remained after DCMU treatment, which was hypothesized to be due to photoexcitation (by PSI) of electrons reaching PSI from the respiratory chain through the plastoquinone pool - an observation that was consistent with ferredoxin (Fd) or NADPH (there is a fast exchange of electrons via ferredoxin:NADPH oxidoreductase in both directions) mediating intracellular electron transfer between the PETC and electron export components. In agreement with this idea, the light effect was completely abolished when methyl viologen (an acceptor of electrons from the reductive end of PSI) was added. Studies using mutant strains of Synechocystis also suggest Fd/NADPH is the substrate for $\left[\mathrm{Fe}(\mathrm{CN})_{6}\right]^{3-}$ reduction at the cytoplasmic membrane ${ }^{\mathbf{1 4 6}}$ (these results will be discussed in more detail later).

Craig et al. ${ }^{148}$ also used $\left[\mathrm{Fe}(\mathrm{CN})_{6}\right]^{3-}$ to measure trans-cytoplasmic membrane electron transfer by Sy. elongatus cells that had been exposed to electron transfer inhibitors. However, these investigators did not observe a difference between light and dark conditions for untreated cells, suggesting that the $S y$. elongatus $\left[\mathrm{Fe}(\mathrm{CN})_{6}\right]^{3-}$ reduction pathway is independent of the PETC - though the lack of an observed difference may possibly have been due to the relatively short incubation period of $\leq 2 \mathrm{~h}$. Whilst the results of inhibitor assays by Craig et al. ${ }^{\mathbf{1 4 8}}$ cannot therefore be compared to those obtained using Synechocystis, the lack of a discernible light effect supports the idea that reducing equivalents are leaving the photosynthetic electron transfer chain and being stored prior to use for $\left[\mathrm{Fe}(\mathrm{CN})_{6}\right]^{3-}$ reduction (e.g. via NADPH and carbon fixation).

Rather than using a soluble extracellular electron acceptor, Pisciotta et al. ${ }^{\mathbf{1 4 9}}$ investigated the effects of inhibitors on electron transfer from Lyngbya sp. or Nostoc sp. to polypyrrolecoated carbon electrodes. Those authors also used DCMU to show that PSII is the source of the photocurrent observed in this system, but concluded that electrons destined for electrode reduction leave the PETC from the plastoquinone pool, as an increase in current was observed when DBMIB (2,5-dibromo-3methyl-6-isopropylbenzoquinone) was used to block plastoquinone oxidation by the cytochrome $b_{6} f$ complex. However, DBMIB can act as a lipid-soluble mediator, which could explain its stimulatory effect on current output. ${ }^{13}$ Excluding this result, the observations of Pisciotta et al. ${ }^{\mathbf{1 4 9}}$ are consistent with electrons leaving the PETC via PSI.

\section{Metabolic mutants}

The creation of deletion mutants is a more specific and complete method of inactivating electron transfer components than using chemical inhibitors. As mentioned earlier, cyanobacterial metabolism is not adapted for exoelectrogenic activity, and a number of mechanisms exist for the dissipation of reductive stress. In addition to being used to probe the intracellular electron transfer pathway leading to electron export, the production of metabolic mutants is an important first step towards the creation of a cyanobacterial strain with a metabolism that is optimized for exoelectrogenesis.
Bradley et al. ${ }^{\mathbf{1 4 6}}$ were the first to analyse the electrogenic activity of mutant strains of a cyanobacterium. Synechocystis possesses three respiratory terminal oxidase complexes (COX, Cyd and ARTO; see Fig. 6) for the reduction of $\mathrm{O}_{2} \cdot{ }^{145}$ Mutant strains lacking RTO (respiratory terminal oxidases) complexes are impaired in their ability to dissipate electrons from the plastoquinone pools, except via PSI when light is provided. Only slightly increased $\left[\mathrm{Fe}(\mathrm{CN})_{6}\right]^{3-}$ reduction rates were observed from the various RTO mutants compared to the wildtype in illuminated conditions, presumably because carbon fixation was available as a sink for photosynthetic reducing power. ${ }^{\mathbf{1 4 6}}$ In dark conditions, however, mutants lacking both thylakoid RTOs (COX and Cyd) showed greatly increased $\left[\mathrm{Fe}(\mathrm{CN})_{6}\right]^{3-}$ reduction rates, while the triple RTO deletion mutant had the greatest increase: a 23-fold higher $\left[\mathrm{Fe}(\mathrm{CN})_{6}\right]^{3-}$ reduction rate than the wild-type when normalized for cell density. These observations are again consistent with Fd/NADPH supplying the 'ferricyanide reductase' activity in Synechocystis, as NADPH generated by metabolite oxidation cannot be oxidized by NDH-1 when the plastoquinone pool is reduced. Furthermore, the intensively studied M55 mutant of Synechocystis $(\Delta n d h B)$, which lacks a functional NDH-1 complex and consequently has an extremely high $\mathrm{NADPH}: \mathrm{NADP}^{+}$ratio, had the highest $\left[\mathrm{Fe}(\mathrm{CN})_{6}\right]^{3-}$ reduction rate of the strains tested. ${ }^{\mathbf{1 4 6 , 1 5 0 , 1 5 1}}$

As would be expected, RTO mutants produced higher power densities than the wild-type strain when they were employed in a BPV device. ${ }^{\mathbf{1 4 6}}$ It was also demonstrated that the triple RTO deletion mutant out-performed the wild-type when utilized to provide reducing equivalents for cathodic $\mathrm{H}_{2}$ production. ${ }^{123}$

\section{Electron export}

Whilst inhibitor and mutant studies have yielded useful information about metabolic pathways that feed cyanobacterial electrogenic activity, the question of how electrons are exported to the periplasmic space or beyond remains unresolved. Reports of electron excretion by photosynthetic organisms are sometimes accompanied by suggestions that this activity allows for the dissipation of excess reducing equivalents e.g. under high light conditions. ${ }^{\mathbf{1 2 6 , 1 4 9 , 1 5 2}}$ Given the extremely low current output from photosynthetic organisms compared to true "electricigens" (e.g. Geobacter spp.), it is unlikely that cyanobacteria possess a specific electron export mechanism for reducing extracellular electron sinks - though a report of conductive extracellular appendages produced by Synechocystis will be examined below. We suggest that the observed current is most likely due to 'leakage' from another redox process, such as assimilatory metal reduction, or oxidation of excreted compounds, though no definite mechanism has yet been identified.

Nanowires from Synechocystis? Gorby et $a .^{36}$ originally reported the presence of conductive 'nanowire' appendages in cultures of $S$. oneidensis MR-1 and other Gram-negative bacteria, including Synechocystis - however, this remains the only paper to present evidence that a high-capacity electron export system might exist in cyanobacteria. Do the observations of Gorby 
et $a l{ }^{36}$ fit with what is known about the Geobacter spp. and $S$. oneidensis nanowire paradigms?

The 100-150 nm thick filaments observed by Gorby et al. ${ }^{36}$ are not consistent with individual type IV pili; electron micrographs of Synechocystis type IV pili show they are 6-8 $\mathrm{nm}$ thick. ${ }^{153}$ A possible explanation is that these appendages may be bundles of 'thin' pili. ${ }^{154}$ Gorby et al. ${ }^{36}$ also noted that aggregates of Synechocystis formed when they cultured the cells under the low $\mathrm{CO}_{2}$ conditions that induced 'nanowire' formation, a behaviour which has been associated with bundling of pili. ${ }^{155} \mathrm{It}$ is also possible that the observed structures are membrane extensions, similar to those recently described by Pirbadian et al. ${ }^{68}$ though this explanation still requires an accompanying hypothesis to explain the observed conductive properties of the Synechocystis structures. No extracellular cytochromes are predicted from the Synechocystis genome sequence, and, according to the model of Schultze et al. ${ }^{\mathbf{1 1 0}}$ (i.e. Fig. 6), no c-type cytochromes are present in the cytoplasmic membrane or periplasm. ${ }^{110,156}$ This contrasts with the fact that extracellular cytochromes are required for the $S$. oneidensis MR-1 extracellular filaments to be conductive. ${ }^{36,157}$ In fact, to the best of our knowledge, all currently described direct-contact exoelectrogenic mechanisms employ c-type cytochromes at and/or beyond the outer surface of the organism..$^{\mathbf{5 3 , 1 5 8 , 1 5 9}}$ Further experimentation is required to confirm the observations of conductive extracellular structures produced by Synechocystis, and to demonstrate their role in electron export. Without additional evidence, it seems more likely that cyanobacteria do not possess a DEET mechanism.

Assimilatory metal reduction. What other processes could be responsible for the current excretion observed in cyanobacteria? With regard to $\left[\mathrm{Fe}(\mathrm{CN})_{6}\right]^{3-}$ reduction, we suggest that assimilatory ferric reductase activity is the most likely candidate.

Kranzler et al. ${ }^{\mathbf{1 6 0}}$ have presented evidence that the cytoplasmic membrane-localised alternative respiratory terminal oxidase (ARTO) complex has a role in assimilatory $\mathrm{Fe}$ (III) reduction in Synechocystis. A mutant strain lacking ARTO reduced Fe(III) EDTA more slowly than the wild-type, though further investigations are required to determine whether ARTO is directly or indirectly (i.e. by facilitating turnover of the cytoplasmic membrane plastoquinone pool) involved in the electron transfer process, and whether this activity is responsible for electron export to an electrode. Experiments conducted by Bradley et al. ${ }^{\mathbf{1 4 6}}$ using mutant strains of Synechocystis with $\left[\mathrm{Fe}(\mathrm{CN})_{6}\right]^{3-}$ as the electron acceptor at the cell surface found that deletion of ARTO improved exoelectrogenic activity, suggesting that a different electron export pathway is used for reduction of this form of $\mathrm{Fe}(\mathrm{III})$. The ferric reductase enzymes that have been described in algae and plants fit the description of an electron export protein that utilizes NADPH as a substrate and could reduce $\left[\mathrm{Fe}(\mathrm{CN})_{6}\right]^{3-}$, but homologues of these proteins are not present in Synechocystis. ${ }^{\mathbf{1 6 1 , 1 6 2}}$ Instead, a homologue of a ferric reductase from the nitrogen-fixing, root nodule colonizing bacterium Bradyrhizobium japonicum looks to be the most promising candidate for a ferricyanide reductase in Synechocystis. ${ }^{\mathbf{1 6 3}}$
Endogenous mediators. The identification of a cytoplasmic membrane-localised reductase would only partially explain cyanobacterial electrogenic activity, as reduction of an electrode by a pure photoautotrophic culture without addition of AEMs is possible. ${ }^{\mathbf{1 5 , 1 2 4}}$ Therefore a mechanism for electron transfer from cytoplasmic membrane to extracellular acceptor must exist, presumably via EEM compounds. These EEMs may also be responsible for electron transfer across the cytoplasmic membrane. Alternatively, oxidisable molecules could be excreted by the organism.

A number of bacteria use EEMs to shuttle electrons to an extracellular acceptor, the three best-described classes being phenazines, flavins and quinones. ${ }^{4,48,164-166}$ Phenazine biosynthesis genes are not present in cyanobacteria, ${ }^{\mathbf{1 6 7}}$ and whilst flavin and quinone molecules are produced by cyanobacteria for intracellular electron transfer processes, there is no evidence to suggest that they are synthesized (or actively excreted) for the purpose of extracellular electron transfer. Cyclic voltammetry of cyanobacterial cultures does not reveal detectable redox peaks, ${ }^{168}$ and no homologue of the $S$. oneidensis MR-1 flavin adenine dinucleotide exporter exists in the majority of sequenced cyanobacteria. ${ }^{64}$ It is, however, conceivable that the modest concentrations of flavin or quinone required to transfer the small amount of current observed from cyanobacteria might accumulate in a culture, for example through lysis of dead cells. In addition to factors such as culture growth, the build-up of redox-active compounds in the medium might partially account for the increase in current production observed over time in some systems. ${ }^{15}$

The idea that electrons might be transferred by excreted oxidisable substrates is also speculative. Production of molecular $\mathrm{H}_{2}$ has been suggested as a possible mechanism for electrode reduction by cyanobacteria, ${ }^{51}$ but this explanation is inconsistent with the sustained current output observed in oxygenic conditions, ${ }^{15}$ where the hydrogenase would be expected to be rendered inactive. Cyanobacteria are known to produce organic exudates, ${ }^{169}$ but so far no studies have looked into whether enough oxidisable molecules are excreted to explain the observed current, or whether species that could act as mediators are produced. Another possibility is the production of reactive $\mathrm{O}_{2}$ species. Rose et al. ${ }^{\mathbf{1 7 0}}$ have described the use of superoxide for $\mathrm{Fe}(\mathrm{III})$ reduction and acquisition by the filamentous cyanobacterium Lyngbya majuscula. The flavoprotein inhibitor diphenyleneiodonium chloride was used in the same study to show that electrons for superoxide production were supplied by $\mathrm{NAD}(\mathrm{P}) \mathrm{H}$, though the specific enzyme responsible was not identified. Superoxide-producing NADPH oxidases have been described in green algae (e.g. C. reinhardtii Respiratory Burst Oxidase-Like proteins). ${ }^{171}$ Recent work has shown that the plasma membrane-localised NADPH oxidase RBO1 is a significant component of light-dependent electron export in BPVs using $C$. reinhardtii. ${ }^{\mathbf{1 3 0}}$ However, no homologues are present in most sequenced cyanobacteria, including Synechocystis.

\section{Achievable power outputs for BPVs}

What advantages can light-dependent BESs (i.e. photoMFCs and BPVs) offer over abiotic photovoltaic cells and other 
agri/algaculture-based photobiological technologies (e.g. cropand algal-based biomass/biofuel production)? Compared to abiotic systems, where expensive processing is required (e.g. generation of crystalline and amorphous semiconductive junctions), light-dependent BESs use living biological components that are relatively cheap to produce and are capable of selfrepair and reproduction. In contrast to agri/algaculture approaches, light-dependent BESs are able to deliver power with no need for downstream processing (e.g. harvesting, transportation and digestion). Light-dependent BESs can also be coupled with agri/algaculture to produce multiple products with the same land area (e.g. seed, biomass and electrical power). Such configurations could also be used to reduce the generation of methane gas associated with crop production. ${ }^{172,173}$ Nevertheless, the present power outputs reported for light-dependent BESs remain too low to produce energy on a commercial scale at a competitive price.

Achievable current and power outputs for optimised lightdependent BESs have been examined previously, but only for complex photoMFC systems. ${ }^{9,18}$ Malik et al. ${ }^{18}$ estimated the maximum achievable current output for a mixed culture-based complex photoMFC to be $20000 \mathrm{~mA} \mathrm{~m}^{-2}$, based on the diffusion limit of $\mathrm{O}_{2}$ to the cathode. Given the reported cell voltage at peak power $(150 \mathrm{mV})$, the maximum achievable power output in their system could be as high as $3000 \mathrm{~mW} \mathrm{~m}{ }^{-2} \cdot{ }^{18}$ A more indepth analysis was performed by Strik et al. ${ }^{9}$ using plant-based complex photoMFCs. Strik et al. ${ }^{9}$ hypothesised that an ideal device would use $\mathrm{a}_{3}$ plant with a photosynthetic efficiency (i.e. light energy into chemical energy as biomass) close to the theoretical maximum (5\%), and which would transport the majority of fixed carbon to the rhizosphere (70\%), with an energy recovery of $60 \%$ from these carbon compounds by the photoMFC system. Assuming a constant solar radiation at ground level (SRG) of $150000 \mathrm{~mW} \mathrm{~m}^{-2}$ as the energy input (i.e. the average SRG of Western Europe), power outputs of $3200 \mathrm{~mW} \mathrm{~m}^{-2}$ would be achievable.

Using a similar approach to that taken by Strik et al. ${ }^{9}$ with plant-based systems, we have estimated an achievable current and power output range for BPVs (ESI Table $2 \dagger$ ). Here, our system is a mediatorless BPV device using cyanobacteria as the light harvesting biomaterial. The microbes are assumed to form a three-dimensional biofilm within a porous transparent anode. The system would operate using light as the sole energy source (i.e. no added organic carbon), with no additional bias potential or anodic/cathodic gas supply/purge.

The SRG inputs used here are based on two city locations in the northern hemisphere: Oslo in the far north $\left(60^{\circ} \mathrm{N}, 103000\right.$ $\left.\mathrm{mW} \mathrm{m}^{-2}\right)$ and Riyadh near the equator $\left(25^{\circ} \mathrm{N}, 263000 \mathrm{~mW} \mathrm{~m}^{-2}\right)$ (as given by the SolarGIS (http://solargis.info/)). At the midpoint wavelength of the photosynthetic active radiation (PAR) range $(370-750 \mathrm{~nm}),^{75} 560 \mathrm{~nm}$, the average light photon flux in Oslo and Riyadh is 481 and $1228 \mu \mathrm{E} \mathrm{m}^{-2} \mathrm{~s}^{-1}$, respectively. The light reactions of photosynthesis can only utilise PAR - roughly $50 \%$ of the available solar light. ${ }^{75}$ The light reactions also do not perfectly absorb PAR, which typically limits maximum interception to approximately $90 \%$ for cyanobacteria. ${ }^{\mathbf{1 7 4}}$ The linear PETC has a theoretical requirement of four moles of photons for generating two moles of electrons for the reduction of one mole of $\mathrm{NADP}^{+}$to NADPH. ${ }^{175}$ However, the photochemical conversion efficiency of light energy into reducing equivalents is typically lower than 100\%; a more conservative estimation suggests five photons per NADPH. ${ }^{75}$

NADPH (and ATP) generated by the light reactions of photosynthesis is then available to the vast complexity of electron sinks within cellular metabolism (e.g. carbon/nitrogen/ metal assimilation; respiration, lipid metabolism, transport processes, secondary metabolite synthesis). ${ }^{176}$ Accounting precisely for all of these potential electron losses is not presently possible. Nevertheless, only a small fraction is considered essential for basic cellular upkeep. Glazier ${ }^{177}$ estimated that only $2-3 \%$ of the fixed carbon stored is used for supporting basal metabolism in unicellular species. For simplicity, here we have assessed two different scenarios. In the first scenario, one third $(33 \%)$ of electrons generated by the photosynthetic light reactions are inexorably lost to other cellular metabolic processes. This assumption is conservative and is likely to exceed the metabolic losses that actually happen. In a second, more optimistic scenario only $3 \%$ of electrons generated by the photosynthetic light reactions are utilised by cellular metabolism. ${ }^{177}$

Finally, electrons must be transferred to an external circuit. MFC studies have reported conversion efficiencies ranging from 60 to $95 \%$ for electron transfer from organic fuels (e.g. acetate) to electrical current. ${ }^{55,178-180}$ Here, we have assumed these values as lower and upper limits of the remaining electrons available for export. Taking into account the combined sum of losses

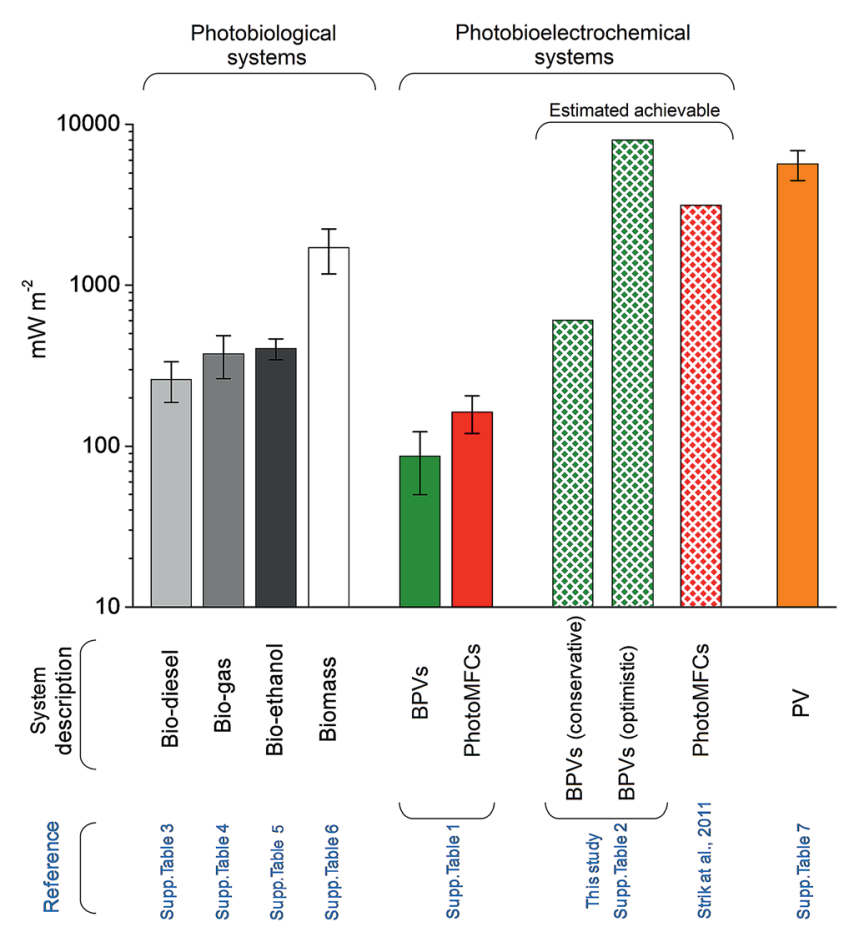

Fig. 7 Actual and theoretical power densities of photobiological, photobioelectrochemical and photovoltaic systems. Figures and means \pm standard errors have been calculated from published data and sources available in ESI Tables 2-7.† 
outlined previously, we can estimate a current output ranging from 3400 to $24600 \mathrm{~mA} \mathrm{~m}^{-2}$.

Calculating the power output requires further assumptions of circuit potential. The maximum achievable voltage depends partly on the redox potential difference between the oxidation of the electron donor at the anode and the reduction of the electron acceptor at the cathode. Additionally, there are several potential energy losses that can take place in a BES system - for review see Logan et al. ${ }^{24}$ In practice, the maximum potential (i.e. the open circuit potential) reported for MFCs is $500-800 \mathrm{mV}$ (ref. 30 and 181) and for light-dependent BESs is 500-700 $\mathrm{mV} .{ }^{87,182}$ At peak power, Xie et al. ${ }^{121}$ demonstrated a drop in potential to $315 \mathrm{mV}$ using a BPV system operated with cyanobacteria. A more conservative estimate $(213 \mathrm{mV})$ was calculated based on the average potentials at peak power reported in $26 \mathrm{BPV}$ studies (ESI Table $1 \dagger$ ). The resulting achievable power outputs range from 700 to $7700 \mathrm{~mW} \mathrm{~m}^{-2}$, (at $3400-24600 \mathrm{~mA} \mathrm{~m}^{-2}$ ), which represents $0.7-2.9 \%$ of the initial power input (ESI Table 2 and Fig. $2 \dagger$ ).

These estimates compares well with achievable energy gains from plant MFCs ${ }^{9,102}$ (Fig. 7). Nevertheless, power outputs of the best present BPV systems achieve only a fraction of this estimate (ca. $86 \mathrm{~mW} \mathrm{~m}^{-2}$ ), indicating that significant improvements are possible - and indeed necessary if this technology is to be of interest outside of the laboratory. A direct comparison with photobiological and photovoltaic technologies (i.e. crop/algal biofuels and PVs, respectively) underlines this weakness. Although the power outputs of present BPVs are comparable to those from photobiological bio-diesel, bio-gas, bio-ethanol or biomass production (ESI Tables 3-6†), the gap with recently built solar power stations $\left(c a .6000 \mathrm{~mW} \mathrm{~m}^{-2}\right.$ ) (ESI Table $\left.7 \dagger\right)$ is substantially larger ( $c a$. 70 -fold). BPVs with improved performances will be a valuable addition to the portfolio of renewable solar technologies, and could be useful for generating electrical power in locations less suited to PVs (e.g. ESI Fig. $3 \dagger$ illustrates a potential future scenario for a marine BPV power station).

The appealing possibility of solar to electrical energy by BPV systems at close to the $2.9 \%$ conversion efficiency calculated here will first and foremost require engineering of the biological material to allow more effective electron export. The current development of tools for synthetic biology (both in general and specifically for cyanobacteria ${ }^{183,184}$ ) will be invaluable to this process. Subsequent changes to the intracellular electron fluxes can then be made through rational redirection of reducing equivalents away from competing sinks, ${ }^{146}$ combined with adaptive evolution to an anodophilic lifestyle. The aim of these changes would be to transmute the organism from a photoautotroph that rarely gains from electron export, to a photo-electricigen that is practically dependent on an extracellular electron sink for survival.

Improvements in the design of the physical BPV device are also required, as considerations specific to photoautotrophic organisms must be taken into account. These improvements might include: optimisation of the anode and cathode to maximise their surface area whilst minimising total geometrical surface area of the device and diffusion distances, enhancement of total light absorption and subsequent distribution to the photocatalytic material, channelling photosynthetic oxygen away from the anode, generation of biomass or valuable coproducts, and tuning the properties of the aqueous media (e.g. $\mathrm{pH}$, salinity) to suit the biological material whilst minimising internal resistance.

BPV systems offer the prospect of an inexpensive light energy capture technology, which comes with the added benefits of being carbon-neutral to produce and run (or possibly even carbon-negative if biomass is harvested and sequestered), and having an inherent ability to store energy. Whilst the efficiencies measured for state of the art BPV systems are far below the theoretical maximum, for the first time in the development of this technology significant steps have been taken to understand and identify the bottlenecks, and new experimental strategies developed to overcome them. We hope the development of BPV technology will provide another valuable tool for the global switch away from carbon-intensive primary energy production.

\section{List of abbreviations}

$\begin{array}{ll}\text { AEM } & \text { Artificial electron mediators } \\ \text { ARTO } & \text { Alternative respiratory terminal oxidase } \\ \text { BES } & \text { Bioelectrochemical system } \\ \text { BPV } & \text { Biophotovoltaic system } \\ \text { COX } & \text { Cytochrome } c \text { oxidase complex } \\ \text { Cyd } & \text { Cytochrome } b d \text {-quinol oxidase complex } \\ \text { DBMIB } & \text { (2,5-Dibromo-3-methyl-6-isopropylbenzoquinone) } \\ \text { DCMU } & \text { (3-(3,4-Dichlorophenyl)-1,1-dimethylurea) } \\ \text { DEET } & \text { Direct extracellular electron transfer } \\ \text { DSSC } & \text { Dye sensitized solar cell } \\ \text { EEM } & \text { Endogenous electron mediator } \\ \text { FC } & \text { Fuel cell } \\ \text { Fd } & \text { Ferredoxin } \\ \text { IEET } & \text { Indirect extracellular electron transfer } \\ \text { MFC } & \text { Microbial fuel cell } \\ \text { OCP } & \text { Open circuit potential } \\ \text { OEC } & \text { Oxygen evolving complex } \\ \text { OPV } & \text { Organic photovoltaic cell } \\ \text { PETC } & \text { Photosynthetic electron transport chain } \\ \text { NADH } & \text { Nicotinamide adenine dinucleotide } \\ \text { NADPH } & \text { Nicotinamide adenine dinucleotide phosphate } \\ \text { PAR } & \text { Photosynthetically active radiation (from } 370 \text { to } 750 \mathrm{~nm} \text { ) } \\ \text { PNS } & \text { Purple nonsulfur } \\ \text { PSI } & \text { Photosystem I } \\ \text { PSII } & \text { Photosystem II } \\ \text { PV } & \text { Photovoltaic cell } \\ \text { RTO } & \text { Respiratory terminal oxidase } \\ \text { SRG } & \text { Solar radiation reaching the ground level } \\ & \end{array}$

\section{Acknowledgements}

We dedicate this to the memory of our colleague Derek Bendall (1930-2014), who contributed much to our work in this area. The authors are grateful for funding provided by the UK Engineering and Physical Sciences Research Council (EPSRC) and EnAlgae (http://www.enalgae.eu/). Tobias Wenzel is grateful for 
funding support from the Winton Programme for the Physics of Sustainability and the Cambridge Home and EU Scholarship Scheme (CHESS). We thank Ross Dennis for illustrations and Robert Bradley for providing additional information at http:// en.wikipedia.org/wiki/Biological_photovoltaics.

\section{References}

1 B. E. Logan, Nat. Rev. Microbiol., 2009, 7, 375-381.

2 H. V. Hamelers, A. Ter Heijne, T. H. Sleutels, A. W. Jeremiasse, D. P. Strik and C. J. Buisman, Appl. Microbiol. Biotechnol., 2010, 85, 1673-1685.

3 M. A. Rosenbaum and A. W. Henrich, Curr. Opin. Biotechnol., 2014, 29C, 93-98.

4 N. S. Lewis and D. G. Nocera, Proc. Natl. Acad. Sci. U. S. A., 2006, 103, 15729-15735.

5 M. Rosenbaum, U. Schröder and F. Scholz, Environ. Sci. Technol., 2005, 39, 6328-6333.

6 A. E. Inglesby, D. A. Beatty and A. C. Fisher, RSC Adv., 2012, 2, 4829.

7 K. Nishio, K. Hashimoto and K. Watanabe, Appl. Microbiol. Biotechnol., 2010, 86, 957-964.

8 M. Rosenbaum, Z. He and L. T. Angenent, Curr. Opin. Biotechnol., 2010, 21, 259-264.

9 D. P. Strik, R. A. Timmers, M. Helder, K. J. Steinbusch, H. V. Hamelers and C. J. Buisman, Trends Biotechnol., 2011, 29, 41-49.

10 D. Gerster, J. Reichert, H. Bi, J. V. Barth, S. M. Kaniber, A. W. Holleitner, I. Visoly-Fisher, S. Sergani and I. Carmeli, Nat. Nanotechnol., 2012, 7, 673-676.

11 O. Yehezkeli, R. Tel-Vered, J. Wasserman, A. Trifonov, D. Michaeli, R. Nechushtai and I. Willner, Nat. Commun., 2012, 3, 742.

$12 \mathrm{~J}$. O. Calkins, Y. Umasankar, H. O'Neill and R. P. Ramasamy, Energy Environ. Sci., 2013, 6, 1891.

13 P. Bombelli, R. W. Bradley, A. M. Scott, A. J. Philips, A. J. McCormick, S. M. Cruz, A. Anderson, K. Yunus, D. S. Bendall, P. J. Cameron, J. M. Davies, A. G. Smith, C. J. Howe and A. C. Fisher, Energy Environ. Sci., 2011, 4, 4690.

14 P. Bombelli, M. Zarrouati, R. J. Thorne, K. Schneider, S. J. Rowden, A. Ali, K. Yunus, P. J. Cameron, A. C. Fisher, D. Ian Wilson, C. J. Howe and A. J. McCormick, Phys. Chem. Chem. Phys., 2012, 14, 12221-12229.

15 A. J. McCormick, P. Bombelli, A. M. Scott, A. J. Philips, A. G. Smith, A. C. Fisher and C. J. Howe, Energy Environ. Sci., 2011, 4, 4699.

16 D. P. B. T. B. Strik, H. V. M. Hamelers, J. F. H. Snel and C. J. N. Buisman, Int. J. Energy Res., 2008, 32, 870-876.

17 X. Cao, X. Huang, P. Liang, N. Boon, M. Fan, L. Zhang and X. Zhang, Energy Environ. Sci., 2009, 2, 498.

18 S. Malik, E. Drott, P. Grisdela, J. Lee, C. Lee, D. A. Lowy, S. Gray and L. M. Tender, Energy Environ. Sci., 2009, 2, 292.

19 Y. Wu, K. Guan, Z. Wang, B. Xu and F. Zhao, PLoS One, 2013, 8, e73442.

20 F. Harnisch and U. Schroder, Chem. Soc. Rev., 2010, 39, 4433-4448.
21 D. R. Lovley, Environ. Microbiol. Rep., 2011, 3, 27-35.

22 M. Rosenbaum, F. Aulenta, M. Villano and L. T. Angenent, Bioresour. Technol., 2011, 102, 324-333.

23 M. C. Potter, Proc. R. Soc. B, 1911, 84, 260-276.

24 B. E. Logan, B. Hamelers, R. Rozendal, U. Schröder, J. Keller, S. Freguia, P. Aelterman, W. Verstraete and K. Rabaey, Environ. Sci. Technol., 2006, 40, 5181-5192.

25 K. Rabaey, G. Lissens and W. Verstraete, in Biofuels for fuel cells: biomass fermentation towards usage in fuel cells, ed. P. Lens, P. Westermann, M. Haberbauer and A. Moreno, IWA Publishing, London, 2006, ch. 20, pp. 377-396.

26 Y. Yang, G. Sun and M. Xu, J. Chem. Technol. Biotechnol., 2011, 86, 625-632.

27 Y. Zhang, J. S. Noori and I. Angelidaki, Energy Environ. Sci., 2011, 4, 4340.

28 B. E. Logan and K. Rabaey, Science, 2012, 337, 686-690.

29 X. Zhu and B. E. Logan, J. Hazard. Mater., 2013, 252-253, 198-203.

30 B. E. Logan, D. Call, S. Cheng, H. V. M. Hamelers, T. H. J. A. Sleutels, A. W. Jeremiasse and R. A. Rozendal, Environ. Sci. Technol., 2008, 42, 8630-8640.

31 M. Mehanna, P. D. Kiely, D. F. Call and B. E. Logan, Environ. Sci. Technol., 2010, 44, 9578-9583.

32 Y. Gong, A. Ebrahim, A. M. Feist, M. Embree, T. Zhang, D. Lovley and K. Zengler, Environ. Sci. Technol., 2013, 47, 568-573.

33 J. Zhang, E. Zhang, K. Scott and J. G. Burgess, Environ. Sci. Technol., 2012, 46, 2984-2992.

34 D. R. Lovley, Geobiology, 2008, 6, 225-231.

35 D. R. Lovley, Energy Environ. Sci., 2011, 4, 4896.

36 Y. A. Gorby, S. Yanina, J. S. McLean, K. M. Rosso, D. Moyles, A. Dohnalkova, T. J. Beveridge, I. S. Chang, B. H. Kim, K. S. Kim, D. E. Culley, S. B. Reed, M. F. Romine, D. A. Saffarini, E. A. Hill, L. Shi, D. A. Elias, D. W. Kennedy, G. Pinchuk, K. Watanabe, S. Ishii, B. Logan, K. H. Nealson and J. K. Fredrickson, Proc. Natl. Acad. Sci. U. S. A., 2006, 103, 11358-11363.

37 Z. M. Summers, H. E. Fogarty, C. Leang, A. E. Franks, N. S. Malvankar and D. R. Lovley, Science, 2010, 330, 1413-1415.

38 Z. Du, H. Li and T. Gu, Biotechnol. Adv., 2007, 25, 464-482. 39 D. R. Bond and D. R. Lovley, Appl. Environ. Microbiol., 2003, 69, 1548-1555.

40 G. Reguera, K. P. Nevin, J. S. Nicoll, S. F. Covalla, T. L. Woodard and D. R. Lovley, Appl. Environ. Microbiol., 2006, 72, 7345-7348.

41 P. S. Bonanni, G. D. Schrott, L. Robuschi and J. P. Busalmen, Energy Environ. Sci., 2012, 5, 6188.

42 B. Salley, P. W. Gordon, A. J. McCormick, A. C. Fisher and D. I. Wilson, Biofouling, 2012, 28, 159-173.

43 C. Leang, N. S. Malvankar, A. E. Franks, K. P. Nevin and D. R. Lovley, Energy Environ. Sci., 2013, 6, 1901-1908.

44 M. Rosenbaum, U. Schroder and F. Scholz, Appl. Microbiol. Biotechnol., 2005, 68, 753-756.

45 D. R. Lovley, J. D. Coates, E. L. Blunt-Harris, E. J. P. Phillips and J. C. Woodward, Nature, 1996, 382, 445-448. 
46 M. E. Hernandez and D. K. Newman, Cell. Mol. Life Sci., 2001, 58, 1562-1571.

47 K. Rabaey, N. Boon, S. D. Siciliano, M. Verhaege and W. Verstraete, Appl. Environ. Microbiol., 2004, 70, 53735382.

48 K. Rabaey, N. Boon, M. Höfte and W. Verstraete, Environ. Sci. Technol., 2005, 39, 3401-3408.

49 E. Marsili, D. B. Baron, I. D. Shikhare, D. Coursolle, J. A. Gralnick and D. R. Bond, Proc. Natl. Acad. Sci. U. S. A., 2008, 105, 3968-3973.

50 Y. Qiao, C. M. Li, S. J. Bao, Z. Lu and Y. Hong, Chem. Commun., 2008, 1290-1292.

51 M. Rosenbaum and U. Schröder, Electroanalysis, 2010, 22, 844-855.

52 D. J. Richardson, J. N. Butt and T. A. Clarke, Proc. Natl. Acad. Sci. U. S. A., 2013, 110, 7537-7538.

53 K. Inoue, C. Leang, A. E. Franks, T. L. Woodard, K. P. Nevin and D. R. Lovley, Environ. Microbiol. Rep., 2011, 3, 211-217.

54 D. R. Lovley, Annu. Rev. Microbiol., 2012, 66, 391-409.

55 K. P. Nevin, H. Richter, S. F. Covalla, J. P. Johnson, T. L. Woodard, A. L. Orloff, H. Jia, M. Zhang and D. R. Lovley, Environ. Microbiol., 2008, 10, 2505-2514.

56 H. Yi, K. P. Nevin, B. C. Kim, A. E. Franks, A. Klimes, L. M. Tender and D. R. Lovley, Biosens. Bioelectron., 2009, 24, 3498-3503.

57 G. T. Feliciano, A. J. da Silva, G. Reguera and E. Artacho, J. Phys. Chem. A, 2012, 116, 8023-8030.

58 M. Vargas, N. S. Malvankar, P. L. Tremblay, C. Leang, J. A. Smith, P. Patel, O. Snoeyenbos-West, K. P. Nevin and D. R. Lovley, mBio, 2013, 4, e00105-00113.

59 N. S. Malvankar, S. E. Yalcin, M. T. Tuominen and D. R. Lovley, Nat. Nanotechnol., 2014, 9, 1012-1017.

60 N. S. Malvankar, M. Vargas, K. P. Nevin, A. E. Franks, C. Leang, B. C. Kim, K. Inoue, T. Mester, S. F. Covalla, J. P. Johnson, V. M. Rotello, M. T. Tuominen and D. R. Lovley, Nat. Nanotechnol., 2011, 6, 573-579.

61 H. Richter, K. P. Nevin, H. Jia, D. A. Lowy, D. R. Lovley and L. M. Tender, Energy Environ. Sci., 2009, 2, 506.

62 N. S. Malvankar and D. R. Lovley, ChemSusChem, 2012, 5, 1039-1046.

63 E. D. Brutinel and J. A. Gralnick, Appl. Microbiol. Biotechnol., 2012, 93, 41-48.

64 N. J. Kotloski and J. A. Gralnick, mBio, 2013, 4, e005533-12. 65 R. S. Hartshorne, B. N. Jepson, T. A. Clarke, S. J. Field,

J. Fredrickson, J. Zachara, L. Shi, J. N. Butt and D. J. Richardson, JBIC, J. Biol. Inorg. Chem., 2007, 12, 1083-1094.

66 L. Shi, K. M. Rosso, J. M. Zachara and J. K. Fredrickson, Biochem. Soc. Trans., 2012, 40, 1261-1267.

67 L. Shi, K. M. Rosso, T. A. Clarke, D. J. Richardson, J. M. Zachara and J. K. Fredrickson, Front. Microbiol., 2012, 3, 50 .

68 S. Pirbadian, S. E. Barchinger, K. M. Leung, H. S. Byun, Y. Jangir, R. A. Bouhenni, S. B. Reed, M. F. Romine, D. A. Saffarini, L. Shi, Y. A. Gorby, J. H. Golbeck and M. Y. El-Naggar, Proc. Natl. Acad. Sci. U. S. A., 2014, 111, 12883-12888.
69 S. Pirbadian and M. Y. El-Naggar, Phys. Chem. Chem. Phys., 2012, 14, 13802-13808.

70 N. F. Polizzi, S. S. Skourtis and D. N. Beratan, Faraday Discuss., 2012, 155, 43-62.

71 R. W. Bradley, P. Bombelli, S. J. Rowden and C. J. Howe, Biochem. Soc. Trans., 2012, 40, 1302-1307.

72 S. B. Velasquez-Orta, T. P. Curtis and B. E. Logan, Biotechnol. Bioeng., 2009, 103, 1068-1076.

73 M. Gratzel, Nature, 2001, 414, 338-344.

74 A. A. Bakulin, S. D. Dimitrov, A. Rao, P. C. Y. Chow, C. B. Nielsen, B. C. Schroeder, I. McCulloch, H. J. Bakker, J. R. Durrant and R. H. Friend, J. Phys. Chem. Lett., 2013, 4, 209-215.

75 D. O. Hall and K. K. Rao, Photosynthesis (Studies in Biology), Cambridge University Press, Cambridge, 1999.

76 A. Badura, T. Kothe, W. Schuhmann and M. Rögner, Energy Environ. Sci., 2011, 4, 3263.

77 K. Nguyen and B. D. Bruce, Biochim. Biophys. Acta, 2014, 1837, 1553-1566.

78 A. F. Janzen and M. Seibert, Nature, 1980, 286, 584-585.

79 R. S. Berk and J. H. Canfield, Appl. Microbiol., 1964, 12, 1012.

80 J. R. Benemann, in Biohydrogen, ed. O. Zaborsky, Plenum Press, New York, 1998, pp. 19-30.

81 Y. K. Cho, T. J. Donohue, I. Tejedor, M. A. Anderson, K. D. McMahon and D. R. Noguera, J. Appl. Microbiol., 2008, 104, 640-650.

82 K. Morishima, M. Yoshida, A. Furuya, T. Moriuchi, M. Ota and Y. Furukawa, J. Micromech. Microeng., 2007, 17, S274S279.

83 D. Xing, Y. Zuo, S. Cheng, J. M. Regan and B. E. Logan, Environ. Sci. Technol., 2008, 42, 4146-4151.

84 F. W. Larimer, P. Chain, L. Hauser, J. Lamerdin, S. Malfatti, L. Do, M. L. Land, D. A. Pelletier, J. T. Beatty, A. S. Lang, F. R. Tabita, J. L. Gibson, T. E. Hanson, C. Bobst, J. L. Torres, C. Peres, F. H. Harrison, J. Gibson and C. S. Harwood, Nat. Biotechnol., 2004, 22, 55-61.

85 E. T. Johnson, D. B. Baron, B. Naranjo, D. R. Bond, C. Schmidt-Dannert and J. A. Gralnick, Appl. Environ. Microbiol., 2010, 76, 4123-4129.

86 A. Melis, L. P. Zhang, M. Forestier, M. L. Ghirardi and M. Seibert, Plant Physiol., 2000, 122, 127-135.

87 Z. He, J. Kan, F. Mansfeld, L. T. Angenent and K. H. Nealson, Environ. Sci. Technol., 2009, 43, 1648-1654.

88 P. Chiranjeevi, R. Chandra and S. V. Mohan, Ecological Engineering, 2013, 51, 181-190.

89 X. Cao, X. Huang, N. Boon, P. Liang and M. Fan, Electrochem. Commun., 2008, 10, 1392-1395.

90 D. P. Strik, H. Terlouw, H. V. Hamelers and C. J. Buisman, Appl. Microbiol. Biotechnol., 2008, 81, 659-668.

91 D. Xing, S. Cheng, J. M. Regan and B. E. Logan, Biosens. Bioelectron., 2009, 25, 105-111.

92 R. Chandra, G. Venkata Subhash and S. Venkata Mohan, Bioresour. Technol., 2012, 109, 46-56.

93 K. Nishio, K. Hashimoto and K. Watanabe, J. Biosci. Bioeng., 2013, 115, 412-417. 
94 P. J. Cai, X. Xiao, Y. R. He, W. W. Li, G. L. Zang, G. P. Sheng, M. H. Lam, L. Yu and H. Q. Yu, Biosens. Bioelectron., 2013, 39, 306-310.

95 A. González del Campo, P. Cañizares, M. A. Rodrigo, F. J. Fernández and J. Lobato, J. Power Sources, 2013, 242, 638-645.

96 P. Bombelli, D. M. Iyer, S. Covshoff, A. J. McCormick, K. Yunus, J. M. Hibberd, A. C. Fisher and C. J. Howe, Appl. Microbiol. Biotechnol., 2013, 97, 429-438.

97 J. Villasenor, P. Capilla, M. A. Rodrigo, P. Canizares and F. J. Fernandez, Water Res., 2013, 47, 6731-6738.

98 L. De Schamphelaire and W. Verstraete, Biotechnol. Bioeng., 2009, 103, 296-304.

99 Y. Hubenova and M. Mitov, Bioelectrochemistry, 2014.

100 N. Kaku, N. Yonezawa, Y. Kodama and K. Watanabe, Appl. Microbiol. Biotechnol., 2008, 79, 43-49.

101 M. Helder, D. P. Strik, H. V. Hamelers, A. J. Kuhn, C. Blok and C. J. Buisman, Bioresour. Technol., 2010, 101, 35413547.

102 K. Wetser, E. Sudirjo, C. J. N. Buisman and D. P. B. T. B. Strik, Appl. Energy, 2015, 137, 151-157.

103 P. D. Kiely, J. M. Regan and B. E. Logan, Curr. Opin. Biotechnol., 2011, 22, 378-385.

104 M. Kato, T. Cardona, A. W. Rutherford and E. Reisner, J. Am. Chem. Soc., 2012, 134, 8332-8335.

105 W. Ryu, S.-J. Bai, J. S. Park, Z. Huang, J. Moseley, T. Fabian, R. J. Fasching, A. R. Grossman and F. B. Prinz, Nano Lett., 2010, 10, 1137-1143.

106 R. Carpentier, S. Lemieux, M. Mimeault, M. Purcell and D. C. Goetze, Bioelectrochem. Bioenerg., 1989, 22, 391-401.

107 K. B. Lam, E. A. Johnson, M. Chiao and L. Lin, J. Microelectromech. Syst., 2006, 15, 1243-1250.

108 J. A. Raven, Physiol. Plant., 2011, 142, 87-104.

109 M. E. Rumpho, E. J. Summer and J. R. Manhart, Plant Physiol., 2000, 123, 29-38.

110 M. Schultze, B. Forberich, S. Rexroth, N. G. Dyczmons, M. Roegner and J. Appel, Biochim. Biophys. Acta, 2009, 1787, 1479-1485.

111 H. Ochiai, H. Shibata, Y. Sawa, M. Shoga and S. Ohta, Appl. Biochem. Biotechnol., 1983, 8, 289-303.

112 K. Tanaka, N. Kashiwagi and T. Ogawa, J. Chem. Technol. Biotechnol., 1988, 42, 235-240.

113 T. Yagishita, S. Sawayama, K. I. Tsukahara and T. Ogi, J. Ferment. Bioeng., 1998, 85, 546-549.

114 K. B. Lam, M. Chiao and L. Lin, Presented in part at the The Sixteenth Annual International Conference on Micro Electro Mechanical Systems, 2003, MEMS-03 Kyoto, IEEE, 2003.

115 N. Martens and E. A. H. Hall, Photochem. Photobiol., 1994, 59, 91-98.

116 T. Yagishita, T. Horigome and K. Tanaka, J. Chem. Technol. Biotechnol., 1993, 56, 393-399.

117 T. Yagishita, S. Sawayama, K.-i. Tsukahara and T. Ogi, Bioelectrochem. Bioenerg., 1997, 43, 177-180.

118 T. Yagishita, S. Sawayama, K. Tsukahara and T. Ogi, J. Biosci. Bioeng., 1999, 88, 210-214.

119 M. Torimura, A. Miki, A. Wadano, K. Kano and T. Ikeda, J. Electroanal. Chem., 2001, 496, 21-28.
120 S. Tsujimura, A. Wadano, K. Kano and T. Ikeda, Enzyme Microb. Technol., 2001, 29, 225-231.

121 X.-H. Xie, E. L. Li and Z. Kang Tang, J. Chem. Technol. Biotechnol., 2011, 86, 109-114.

122 R. Thorne, H. Hu, K. Schneider, P. Bombelli, A. Fisher, L. M. Peter, A. Dent and P. J. Cameron, J. Mater. Chem., 2011, 21, 18055.

123 A. J. McCormick, P. Bombelli, D. J. Lea-Smith, R. W. Bradley, A. M. Scott, A. C. Fisher, A. G. Smith and C. J. Howe, Energy Environ. Sci., 2013, 6, 2682.

124 Y. Zou, J. Pisciotta, R. B. Billmyre and I. V. Baskakov, Biotechnol. Bioeng., 2009, 104, 939-946.

125 J. M. Pisciotta, Y. Zou and I. V. Baskakov, PLoS One, 2010, 5, e10821.

126 A. Cereda, A. Hitchcock, M. D. Symes, L. Cronin, T. S. Bibby and A. K. Jones, PLoS One, 2014, 9, e91484.

127 N. Samsonoff, M. D. Ooms and D. Sinton, Appl. Phys. Lett., 2014, 104, 043704.

128 V. M. Luimstra, S.-J. Kennedy, J. Güttler, S. A. Wood, D. E. Williams and M. A. Packer, J. Appl. Phycol., 2013, 26, 15-23.

129 F. L. Ng, S. M. Phang, V. Periasamy, K. Yunus and A. C. Fisher, PLoS One, 2014, 9, e97643.

130 A. Anderson, A. Laohavisit, I. Blaby, P. Bombelli, C. Howe, S. Merchant, A. Smith and J. Davies, Plant Biotechnol. J., 2015, DOI: 10.1111/pbi.12332.

131 K. S. Madiraju, D. Lyew, R. Kok and V. Raghavan, Bioresour. Technol., 2012, 110, 214-218.

132 P. Bombelli, T. Müller, T. W. Herling, C. J. Howe and T. P. J. Knowles, Adv. Energy Mater., 2015, 5, 1401299.

133 C. Y. Chen, T. Y. Chen and Y. C. Chung, Environ. Technol., 2014, 35, 286-293.

134 C. C. Fu, C. H. Su, T. C. Hung, C. H. Hsieh, D. Suryani and W. T. Wu, Bioresour. Technol., 2009, 100, 4183-4186.

135 C.-C. Fu, T.-C. Hung, W.-T. Wu, T.-C. Wen and C.-H. Su, Biochem. Eng. J., 2010, 52, 175-180.

136 A. E. Inglesby, K. Yunus and A. C. Fisher, Phys. Chem. Chem. Phys., 2013, 15, 6903-6911.

137 F. Harnisch, S. Wirth and U. Schröder, Electrochem. Commun., 2009, 11, 2253-2256.

138 A. M. van de Meene, M. F. Hohmann-Marriott, W. F. Vermaas and R. W. Roberson, Arch. Microbiol., 2006, 184, 259-270.

139 D. Smith and C. J. Howe, FEMS Microbiol. Lett., 1993, 110, 341-347.

140 D. Schneider, E. Fuhrmann, I. Scholz, W. R. Hess and P. L. Graumann, BMC Cell Biol., 2007, 8, 39.

141 P. Zhang, M. Eisenhut, A. M. Brandt, D. Carmel, H. M. Silen, I. Vass, Y. Allahverdiyeva, T. A. Salminen and E. M. Aro, Plant Cell, 2012, 24, 1952-1971.

142 L. Bersanini, N. Battchikova, M. Jokel, A. Rehman, I. Vass, Y. Allahverdiyeva and E. M. Aro, Plant Physiol., 2014, 164, 805-818.

143 S. E. Hart, B. G. Schlarb-Ridley, D. S. Bendall and C. J. Howe, Biochem. Soc. Trans., 2005, 33, 832-835.

144 D. Pils, W. Gregor and G. Schmetterer, FEMS Microbiol. Lett., 2006, 152, 83-88. 
145 D. J. Lea-Smith, N. Ross, M. Zori, D. S. Bendall, J. S. Dennis, S. A. Scott, A. G. Smith and C. J. Howe, Plant Physiol., 2013, 162, 484-495.

146 R. W. Bradley, P. Bombelli, D. J. Lea-Smith and C. J. Howe, Phys. Chem. Chem. Phys., 2013, 15, 13611-13618.

147 W. Oettmeier and H.-J. Soll, Biochim. Biophys. Acta, Bioenerg., 1983, 724, 287-290.

148 T. A. Craig, F. L. Crane, P. C. Misra and R. Barr, Plant Sci. Lett., 1984, 35, 11-17.

149 J. M. Pisciotta, Y. Zou and I. V. Baskakov, Appl. Microbiol. Biotechnol., 2011, 91, 377-385.

150 T. Ogawa, Proc. Natl. Acad. Sci. U. S. A., 1991, 88, 4275-4279.

151 J. W. Cooley and W. F. Vermaas, J. Bacteriol., 2001, 183, 4251-4258.

152 M. S. Davey, D. J. Suggett, R. J. Geider and A. R. Taylor, J. Phycol., 2003, 39, 1132-1144.

153 D. Bhaya, N. R. Bianco, D. Bryant and A. Grossman, Mol. Microbiol., 2000, 37, 941-951.

154 S. Yoshihara, Plant Cell Physiol., 2001, 42, 63-73.

155 K. Nakasugi, C. J. Svenson and B. A. Neilan, Microbiology, 2006, 152, 3623-3631.

156 Y. Kanesaki, Y. Shiwa, N. Tajima, M. Suzuki, S. Watanabe, N. Sato, M. Ikeuchi and H. Yoshikawa, DNA research: an international journal for rapid publication of reports on genes and genomes, 2012, 19, 67-79.

157 M. Y. El-Naggar, G. Wanger, K. M. Leung, T. D. Yuzvinsky, G. Southam, J. Yang, W. M. Lau, K. H. Nealson and Y. A. Gorby, Proc. Natl. Acad. Sci. U. S. A., 2010, 107, 18127-18131.

158 L. Shi, T. C. Squier, J. M. Zachara and J. K. Fredrickson, Mol. Microbiol., 2007, 65, 12-20.

159 K. C. Wrighton, J. C. Thrash, R. A. Melnyk, J. P. Bigi, K. G. Byrne-Bailey, J. P. Remis, D. Schichnes, M. Auer, C. J. Chang and J. D. Coates, Appl. Environ. Microbiol., 2011, 77, 7633-7639.

160 C. Kranzler, H. Lis, O. M. Finkel, G. Schmetterer, Y. Shaked and N. Keren, ISME J., 2014, 8, 409-417.

161 M. D. Allen, J. A. del Campo, J. Kropat and S. S. Merchant, Eukaryotic Cell, 2007, 6, 1841-1852.

162 X. Zhang, K. H. Krause, I. Xenarios, T. Soldati and B. Boeckmann, PLoS One, 2013, 8, e58126.

163 S. K. Small and M. R. O'Brian, J. Bacteriol., 2011, 193, 40884094.

164 D. K. Newman and R. Kolter, Nature, 2000, 405, 94-97.
165 H. von Canstein, J. Ogawa, S. Shimizu and J. R. Lloyd, Appl. Environ. Microbiol., 2008, 74, 615-623.

166 M. E. Hernandez, A. Kappler and D. K. Newman, Appl. Environ. Microbiol., 2004, 70, 921-928.

167 D. V. Mavrodi, T. L. Peever, O. V. Mavrodi, J. A. Parejko, J. M. Raaijmakers, P. Lemanceau, S. Mazurier, L. Heide, W. Blankenfeldt, D. M. Weller and L. S. Thomashow, Appl. Environ. Microbiol., 2010, 76, 866-879.

168 Y. Zou, J. Pisciotta and I. V. Baskakov, Bioelectrochemistry, 2010, 79, 50-56.

169 A. E. Kirkwood, C. Nalewajko and R. R. Fulthorpe, Microb. Ecol., 2006, 51, 4-12.

170 A. L. Rose, T. P. Salmon, T. Lukondeh, B. A. Neilan and T. D. Waite, Environ. Sci. Technol., 2005, 39, 3708-3715.

171 A. Anderson, J. H. Bothwell, A. Laohavisit, A. G. Smith and J. M. Davies, Trends Plant Sci., 2011, 16, 579-581.

172 L. D. Schamphelaire, L. V. d. Bossche, H. S. Dang, M. Höfte, N. Boon, K. Rabaey and W. Verstraete, Environ. Sci. Technol., 2008, 42, 3053-3058.

173 J. B. Arends, J. Speeckaert, E. Blondeel, J. De Vrieze, P. Boeckx, W. Verstraete, K. Rabaey and N. Boon, Appl. Microbiol. Biotechnol., 2014, 98, 3205-3217.

174 D. J. Lea-Smith, P. Bombelli, J. S. Dennis, S. A. Scott, A. G. Smith and C. J. Howe, Plant Physiol., 2014, 165, 705714.

175 X. G. Zhu, S. P. Long and D. R. Ort, Annu. Rev. Plant Biol., 2010, 61, 235-261.

176 H. Knoop, M. Grundel, Y. Zilliges, R. Lehmann, S. Hoffmann, W. Lockau and R. Steuer, PLoS Comput. Biol., 2013, 9, e1003081.

177 D. S. Glazier, Functional Ecology, 2009, 23, 963-968.

178 S. E. Oh and B. E. Logan, Water Res., 2005, 39, 4673-4682.

179 S. Freguia, K. Rabaey, Z. Yuan and J. Keller, Environ. Sci. Technol., 2007, 41, 2915-2921.

180 C. I. Torres, A. K. Marcus and B. E. Rittmann, Appl. Microbiol. Biotechnol., 2007, 77, 689-697.

181 Y. Kim, M. C. Hatzell, A. J. Hutchinson and B. E. Logan, Energy Environ. Sci., 2011, 4, 4662.

182 C. C. Lin, C. H. Wei, C. I. Chen, C. J. Shieh and Y. C. Liu, Bioresour. Technol., 2013, 135, 640-643.

183 H. H. Huang, D. Camsund, P. Lindblad and T. Heidorn, Nucleic Acids Res., 2010, 38, 2577-2593.

184 B. M. Berla, R. Saha, C. M. Immethun, C. D. Maranas, T. S. Moon and H. B. Pakrasi, Front. Microbiol., 2013, 4, 246. 